Research Article

\title{
Evaluation of Particulate Matter Capture and Long-Term Clogging Characteristics of Different Filter Media for Pavement Runoff Treatment
}

\author{
Zhengguang Wu, ${ }^{1}$ Yanjuan Qi, ${ }^{1}$ Aihong Kang ${ }^{D},{ }^{1}$ Bo Li ${ }^{D},{ }^{1}$ and Xueling $\mathrm{Xu}^{2}$ \\ ${ }^{1}$ College of Civil Science and Engineering, Yangzhou University, Yangzhou 225127, China \\ ${ }^{2}$ Shanghai Telsafe Engineering Technology Co., Ltd., Shanghai 200120, China \\ Correspondence should be addressed to Aihong Kang; ahkang@yzu.edu.cn
}

Received 27 June 2020; Accepted 14 July 2020; Published 27 August 2020

Guest Editor: Hainian Wang

Copyright (c) 2020 Zhengguang Wu et al. This is an open access article distributed under the Creative Commons Attribution License, which permits unrestricted use, distribution, and reproduction in any medium, provided the original work is properly cited.

\begin{abstract}
The removal of particulate matter (PM) by filter media during filtration process can mitigate the pavement runoff pollution effectively. However, this process also makes the filter media prone to clogging. To better understand the size ranges of PM captured by filter media and the subsequent impact on the clogging process, filtration test and clogging test were conducted on five types of filter media. The effect of layer thickness and grain size of different filter media on particle removal efficiency was evaluated, based on the results of PM removal rate and the particle size distribution. The subsequent long-term clogging characteristics of different filter media were also investigated. The results showed that filter media presented different capabilities to capture PM, which could be enhanced by less layer thickness or finer grain size. Normally, PM with the size range of over $49 \mu \mathrm{m}$ could be captured effectively if proper layer thickness and grain size of filter media were selected. Besides, PM removal rate was not related to the clogging resistance of filter media. Though it can capture a larger amount of PM, Vesuvianite still maintained remarkable clogging resistance. The results will be beneficial to filter media selection and system design optimization for pavement runoff treatment.
\end{abstract}

\section{Introduction}

Pavement runoff has been considered as a major pollution source to adjacent receiving watershed [1-3]. The pollutants in pavement runoff mainly consist of particulate matter (normally characterized by total suspended solids, TSS), chemical oxygen demand (COD), nutrients (normally characterized by total nitrogen, TN, and total phosphorus, TP) and heavy metals [4], which commonly have highly polluted concentrations $[5,6]$. Filtration and infiltration systems are effective in mitigating the pavement runoff pollution [7-11], although the systems were developed initially to control the runoff volumes.

Unfortunately, those systems are prone to clogging, leading to deterioration in (in)filtration capability $[7,12]$. Filtration and infiltration systems are normally filled with specified filter media (Figure 1), such as Zeolite, Diatomite, expanded vermiculite, Ceramsite, Vesuvianite, furnace/steel Slag [13], and granular activated carbon [14], along with conventional filter media such as soil, sand, and gravel. The pore structures of filter media will be blocked gradually as the suspended PM is captured [15-18]. Therefore, the suspended PM in runoff has been considered as a dominant contributor to clogging $[19,20]$.

The PM in pavement runoff originates from road-deposited sediments accumulated on the pavement surfaces, which will be washed off during rainy days [13]. The concentration and the particle size distribution (PSD) of PM are highly related to the clogging phenomenon. Research has been conducted to characterize the PM in pavement runoff. In addition to the widely used gravimetric concentration indices of TSS and turbidity, PSD of PM has also been 


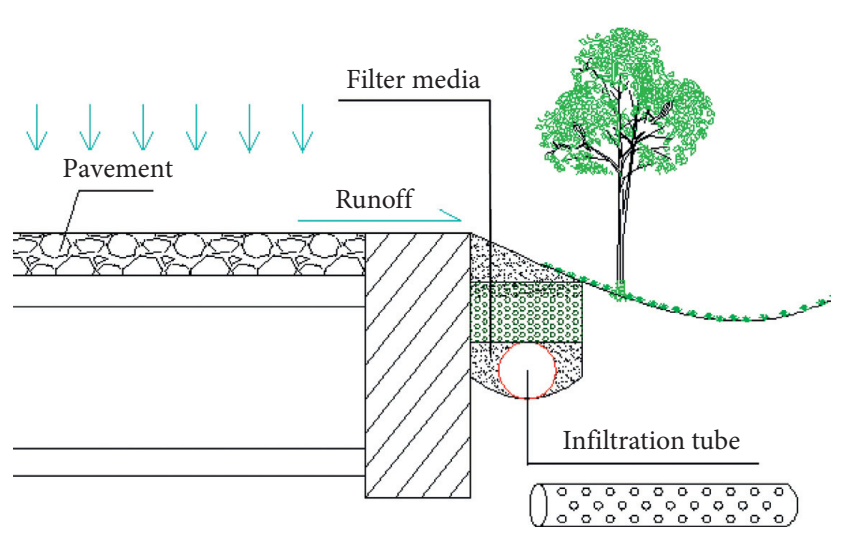

FIgURE 1: Illustration of an infiltration gutter system.

determined. Charters [21] investigated PSD in the untreated runoff collected from pavement, concrete roof, copper roof, etc., in New Zealand, and the results showed that pavement runoff contained much higher TSS concentration, while the peak particle size range was between 60 and $100 \mu \mathrm{m}$. Shen et al. [22] characterized PSD in pavement and roof runoff in Beijing and found out that particles with the size ranges of $38-74 \mu \mathrm{m}$ and $125-300 \mu \mathrm{m}$ accounted for the majority of the PM in pavement runoff. Winston's research [23] revealed that median particle size of PM varied from 31 to $144 \mu \mathrm{m}$ according to 43 road runoff events in North Carolina. Li et al. [24] monitored three highways in west Los Angeles for three rainfall events, and the results showed that more than $97 \%$ of the particles had a size of less than $30 \mu \mathrm{m}$. Jartun et al. [25] investigated 21 runoff samples in Norway and reported that the particle size varied from $13 \mu \mathrm{m}$ to $646 \mu \mathrm{m}$. In general, the PM in untreated pavement runoff has normally a size range of $0-1000 \mu \mathrm{m}$.

Due to the differences in angularity, texture, chemical compositions, etc., different types of filter media are supposed to possess various pore structures $[26,27]$ and capabilities to capture particulate matter. Furthermore, the PSD changes of PM in runoff treated by filter media can not only reflect the capability of filter media to capture PM, but also infer the size ranges of captured PM which will cause clogging. However, current research focused on the PSD analysis of untreated pavement runoff. Few studies have been performed to evaluate the PSD changes in treated runoff. Therefore, it is still not well understood which size ranges of PM could be captured by filter media and the subsequent impact on the clogging process.

Therefore, the primary objective of this study was to evaluate the capability to capture PM and the corresponding clogging characteristics of different types of filter media. To achieve the objective, synthetic runoff was prepared according to in situ pavement runoff. Then, the PM removal rate of five types of filter media, with different layer thickness and grain size, was investigated by laboratory filtration test. Moreover, the PSD changes in the untreated and treated runoff were determined by a laser particle analyzer, and the PM capture capability of the filter media was comprehensively analyzed. Eventually, long-term clogging simulation tests were conducted so as to evaluate the clogging characteristics of the five filter media.

The methodology of this research is depicted in Figure 2.

\section{Materials and Experimental Methods}

2.1. Synthetic Runoff Preparation. Considering that a large amount of runoff with stable and consistent characteristics was required for the laboratory test, synthetic runoff was prepared as an alternative, according to the previous investigation results of the in situ pavement runoff [13]. Synthetic runoff was prepared by dissolving pavement deposited dust and chemical compounds into deionized water. The target concentrations and selected chemical compounds are listed in Table 1.

As shown in Table 1, the heavy metal elements of $\mathrm{Zn}$ and $\mathrm{Pb}$, which mainly originate from vehicle tires and fuels, respectively, were selected for analysis, since they are the dominant ones in pavement runoff. The PSD of the synthetic runoff, which was close to that of in situ pavement runoff, had $d_{50}$ and $d_{90}$ of $193.6 \mu \mathrm{m}$ and $400.7 \mu \mathrm{m}$, respectively.

2.2. Filter Media. Five typical types of filter media used in filtration systems were chosen for this study, which were Zeolite, Ceramsite, Slag, Diatomite, and Vesuvianite. They possess various porous structures and compositions (Figure 3) and can capture particulate matter by retention and/or absorption, along with some other physical and chemical interactions [13]. Besides, three different grain sizes of 1-3 $\mathrm{mm}, 3-6 \mathrm{~mm}$, and 6-8 $\mathrm{mm}$, which are widely applied in engineering projects, were also prepared for each filter medium.

Air-void fraction of every filter medium with each grain size was investigated in accordance with Chinese standard CJ/T 299. The loose filled bulk density and apparent density of filter media were tested. The air-void fraction can be calculated by

$$
v=\left(1-\frac{\rho_{b}}{\rho_{a p}}\right) \times 100,
$$

where $v$ is the air-void faction, \%; $\rho_{b}$ is the loose filled bulk density, $\mathrm{g} / \mathrm{cm}^{3}$; and $\rho_{a p}$ is the apparent density, $\mathrm{g} / \mathrm{cm}^{3}$.

2.3. Filtration Test. Filtration test was performed to evaluate the capability of filter media to capture particulate matter by self-developed equipment, as shown in Figure 4. This equipment mainly contained three parts: a storage bucket, a pump, and a column. The bucket with a blender was used to supply homogeneous pavement runoff. The pump was equipped with a flow meter so as to control the flow rate. The column was $14 \mathrm{~cm}$ in diameter and $50 \mathrm{~cm}$ in height, respectively. Four overflow valves were designed vertically on the column with an interval of $10 \mathrm{~cm}$.

In order to investigate the effect of layer thickness and grain size of filter media on the removal efficiency of PM, three layer thickness levels of $10 \mathrm{~cm}, 20 \mathrm{~cm}$, and $30 \mathrm{~cm}$ and three grain size levels of 1-3 $\mathrm{mm}, 3-6 \mathrm{~mm}$, and 6-8 $\mathrm{mm}$ were 
Raw materials and equipment

(i) Synthetic runoff preparation

(ii) Filter media selection

(iii) Self-developed filtration test equipment
Filtration test

Evaluation of the PM capture capability of filter media

(i) Layer thickness and grain size of filter media

(ii) Changes in PM removal rate

(iii) Changes in PSD of PM in runoff
Analysis and discussion

(i) Particle sizes of PM causing clogging

(ii) PM capture capability \& clogging resistance

(iii) Optimum maintenance timing
Long-term clogging test

Evaluation of clogging characteristics of filter media

(i) Changes in hydraulic conductivity over time

(ii) Changes in pollutant removal rates over time

(iii) Clogging stage determination

FIgURe 2: Illustration of research plan.

TABLe 1: Pollutant characteristics of synthetic pavement runoff.

\begin{tabular}{|c|c|c|c|c|c|c|}
\hline Types of pollutants & TSS & COD & $\mathrm{TN}$ & $\mathrm{TP}$ & $\mathrm{Zn}$ & $\mathrm{Pb}$ \\
\hline $\begin{array}{l}\text { Target concentration }(\mathrm{mg} / \mathrm{L}) \\
\text { Substance } \\
\text { Test methods }\end{array}$ & $\begin{array}{c}300 \\
\text { Road-deposited dust } \\
\text { GB/T } 11914\end{array}$ & $\begin{array}{c}250 \\
\mathrm{C}_{6} \mathrm{H}_{12} \mathrm{O}_{6} \\
\mathrm{~GB} / \mathrm{T} 11901\end{array}$ & $\begin{array}{l}10 \\
\mathrm{NH}_{4} \mathrm{Cl} \\
\mathrm{HJ} 636\end{array}$ & $\begin{array}{c}1.5 \\
\mathrm{KH}_{2} \mathrm{PO}_{4} \\
\mathrm{~GB} / \mathrm{T} 11893\end{array}$ & $\begin{array}{l}5.0 \\
\mathrm{Zn}\left(\mathrm{NO}_{3}\right)_{2} \\
\mathrm{~GB} 7475\end{array}$ & $\begin{array}{c}2.0 \\
\mathrm{~Pb}\left(\mathrm{NO}_{3}\right)_{2} \\
\mathrm{~GB} 7475\end{array}$ \\
\hline
\end{tabular}

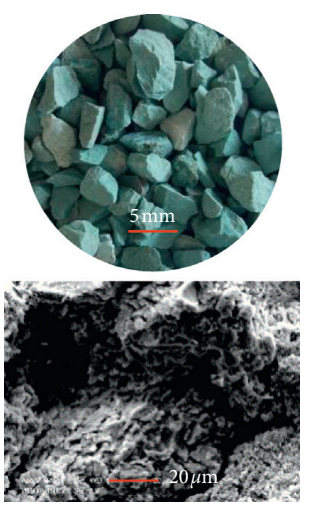

(a)

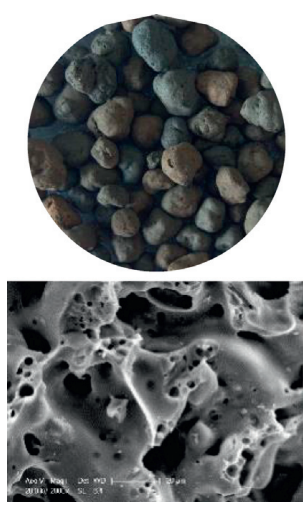

(b)

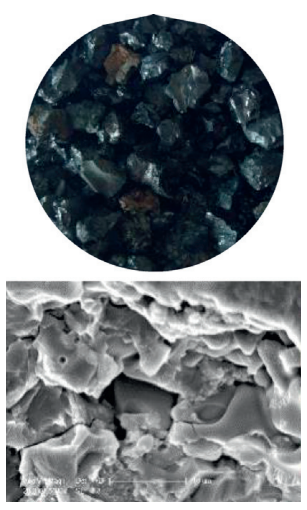

(c)

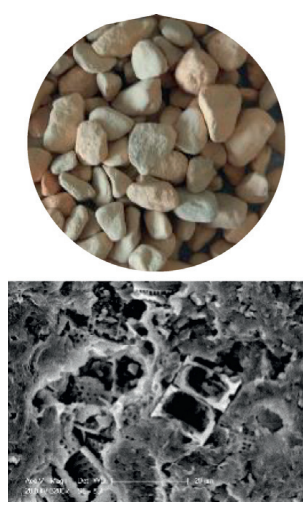

(d)

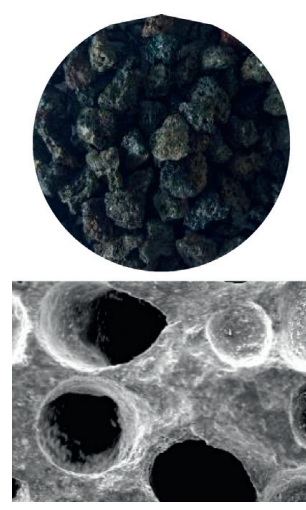

(e)

Figure 3: Surface morphologies and microstructures of the selected filter media. (a) Zeolite. (b) Ceramsite. (c) Slag. (d) Diatomite. (e) Vesuvianite.

selected for each filter medium. In terms of each filtration test, the filter medium was poured into the column to a desired thickness. The constant hydraulic head of $10 \mathrm{~cm}$ was maintained throughout the test by opening the overflow valve which was $10 \mathrm{~cm}$ above the top surface of the media. In order to eliminate its effect on the filtration process, flow rate was controlled at the constant level of $4 \mathrm{~L} / \mathrm{min}$ in this study, according to the moderate daily rainfall in Yangzhou city [13]. Effluent from the outlet of each test was collected to analyze the TSS concentration, so that the index of removal rate can be calculated by (2) for different filter media. Three replicates were conducted for each test and the average values were used for analysis.

$$
\eta=\frac{C_{0}-C_{1}}{C_{0}} \times 100,
$$

where $C_{0}$ is the TSS concentration of influent, $\mathrm{mg} / \mathrm{L}$, and $C_{1}$ is the TSS concentration of effluent, $\mathrm{mg} / \mathrm{L}$.
2.4. Particle Size Distribution Test. The laser particle analyzer of Bettersize 2000 with a detection range of $0.01-800 \mu \mathrm{m}$ was employed to conduct the particle size distribution test. Effluent from each filtration test was collected, and the PSD of the PM was analyzed. Three replicates were carried out for each testing sample. Volume distribution curve was employed to describe the PSD of the PM. The typical diameter indices, referred to as $d_{10}, d_{50}$, and $d_{90}$, were chosen to determine the particle size of the PM. The $d_{50}$ index represents the median diameter, while $d_{10}$ and $d_{90}$ mean the tenth and ninetieth percentile diameter, respectively. Furthermore, the particle size range was divided into six intervals, namely, $0-1 \mu \mathrm{m}, 1-9 \mu \mathrm{m}, \quad 9-49 \mu \mathrm{m}$, $49-161 \mu \mathrm{m}, 161-417 \mu \mathrm{m}$, and $417-800 \mu \mathrm{m}$, to determine the PSD changes in greater detail, according to the PSD result of the PM in each sample.

2.5. Clogging Test. The particulate matter captured by filter media leads to deterioration in hydraulic conductivity. As a 


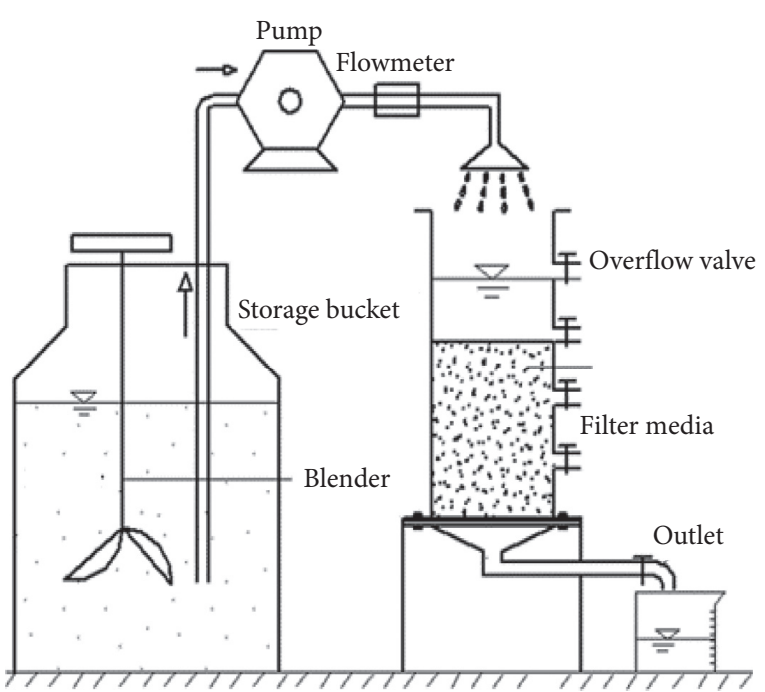

(a)

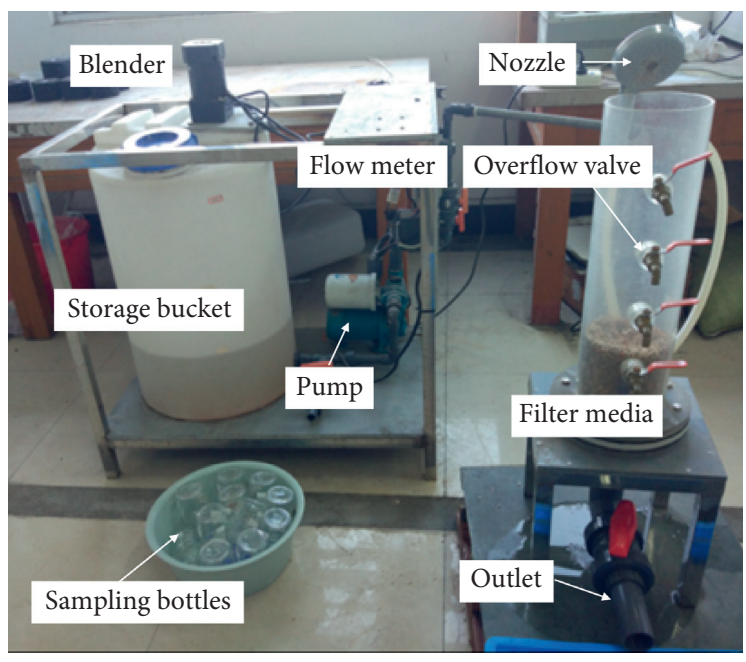

(b)

FIGURE 4: Schematic of filtration test equipment. (a) Diagram of the equipment. (b) Picture view.

result, the clogging characteristics of filter media can be determined by monitoring the changes in hydraulic conductivity as clogging develops. The hydraulic conductivity of each filter medium was measured by constant hydraulic head method using the same equipment as the filtration test (Figure 4). The filter medium was firstly poured into the column to a desired thickness and soaked in deionized water for one hour to saturated status. Then the valve was opened and the water kept flowing though the filter medium. When the hydraulic head and effluent rate were stable, the total volume of the influent through the filter media was recorded within a certain period of time. The hydraulic conductivity can be calculated by

$$
K=\frac{Q L}{A \Delta h t} \times 10
$$

where $K$ is the hydraulic conductivity, $\mathrm{mm} / \mathrm{s} ; Q$ is the total volume of the influent within $t$ seconds, $\mathrm{cm}^{3} ; L$ is the thickness of filter media, $\mathrm{cm} ; A$ is the active cross-sectional area of filter media, $\mathrm{cm}^{2} ; \Delta h$ is the hydraulic head, $\mathrm{cm}$; and $t$ is the filtration time, $s$.

The long-term clogging process was simulated by controlling the gross amount of the particulate matter, which was calculated based on the annual volume and TSS concentrations of pavement runoff in Yangzhou city, when the dry season effect on clogging process was not considered. In this test, one year was taken as one simulation period, and 8 periods were conducted, since, at the end of 8 years simulation running, the hydraulic conductivity of each filter medium has reduced to less than $40 \%$ of the original value, indicating that the filer media lost the required functions. At the end of each simulation period (one year), the hydraulic conductivity was measured. Subsequently, the retained ratio of hydraulic conductivity (RRHC) was defined to evaluate the clogging degree, which was expressed by (4). Besides, the pollutants' concentrations in the effluent were tested, and the resultant removal rate of each pollutant was calculated according to (2).

$$
\varphi=\frac{K_{s j}}{K_{i}} \times 100,
$$

where $\varphi$ is the retained ratio of hydraulic conductivity, \%; $K_{s j}$ is the hydraulic conductivity at simulation period $j$, $j=1,2,3,4,5,6,7,8, \mathrm{~mm} / \mathrm{s}$; and $K_{i}$ is the initial hydraulic conductivity, $\mathrm{mm} / \mathrm{s}$.

\section{Results and Discussion}

\subsection{Particle Removal Efficiency of Different Filter Media}

3.1.1. Effect of Layer Thickness of Filter Media. Three layer thickness levels of $10 \mathrm{~cm}, 20 \mathrm{~cm}$, and $30 \mathrm{~cm}$ were prepared for each filter medium to study the effect of layer thickness on the particle removal efficiency. The grain size of 3-6 mm was selected in this test for each filter medium, since this grain size is the most used one. The removal rate of TSS and the particle size distribution were used to evaluate the particle removal efficiency, so as to assess the size ranges of the particulate matter captured by the filter media during the filtration process. The results of removal rate and PSD from each filter medium are illustrated in Figure 5.

The effect of layer thickness of Zeolite on the particle removal efficiency is shown in Figures 5(a) and 5(b). It can be seen that the removal rate of TSS increased from $69.4 \%$ to $79.0 \%$ as the layer thickness increased from $10 \mathrm{~cm}$ to $20 \mathrm{~cm}$. However, the removal rate remained at the same level when the layer thickness further increased from $20 \mathrm{~cm}$ to $30 \mathrm{~cm}$. Obvious PSD variations could also be observed correspondingly. In terms of the original influent, the particle size of PM was distributed mainly within the intervals of $49-161 \mu \mathrm{m}, 161-417 \mu \mathrm{m}$, and $417-800 \mu \mathrm{m}$, which accounted for $32.2 \%, 42.8 \%$, and $8.7 \%$ of the total particles, respectively. As for the effluent runoff through Zeolite, $100 \%$ of the particles with the size range of $417-800 \mu \mathrm{m}$ were captured by Zeolite, and only a small proportion (3.3\%) of PM with the 


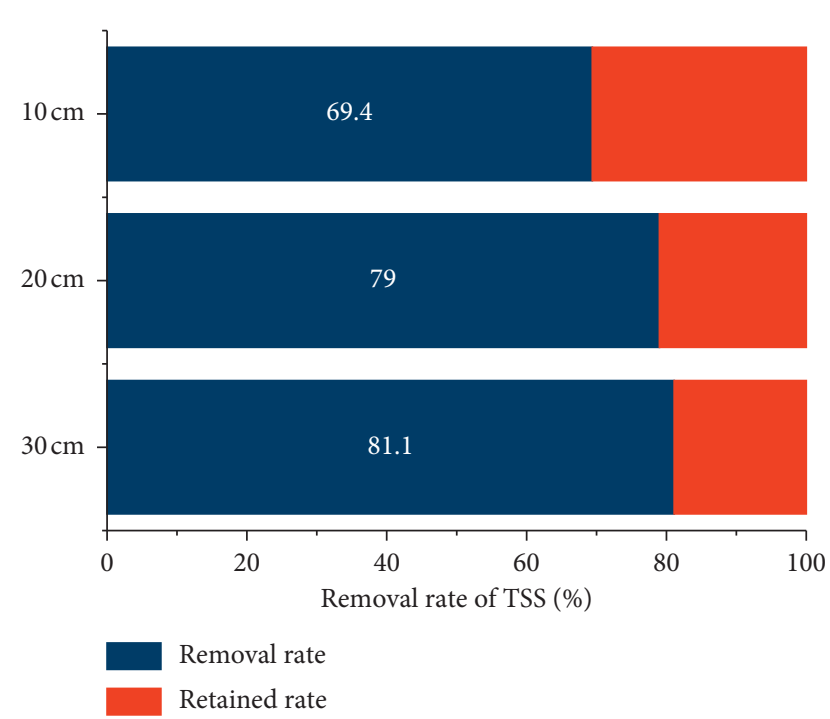

(a)

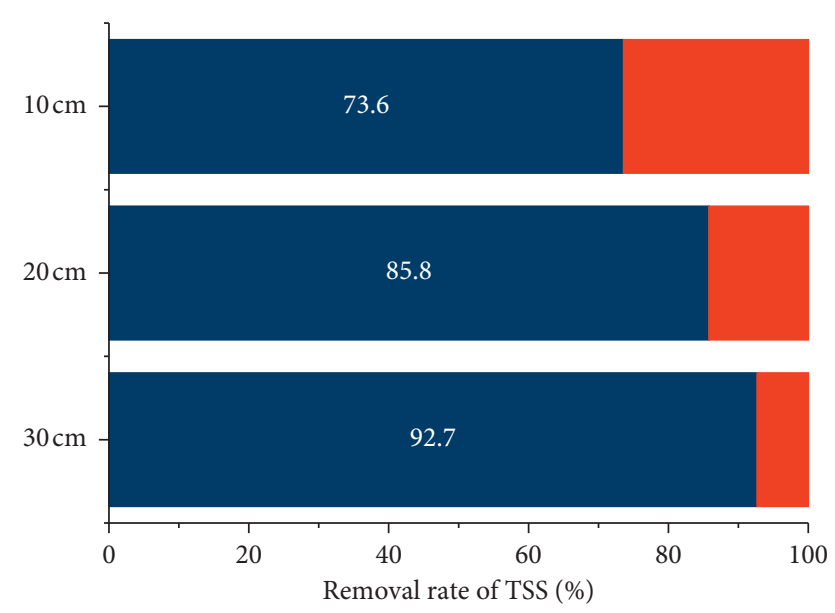

Removal rate

Retained rate

(c)

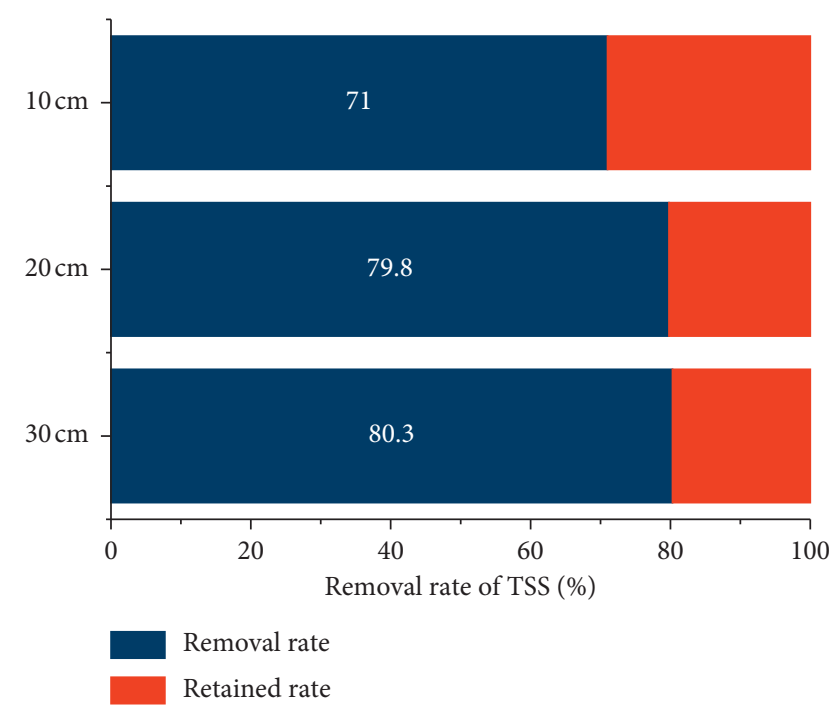

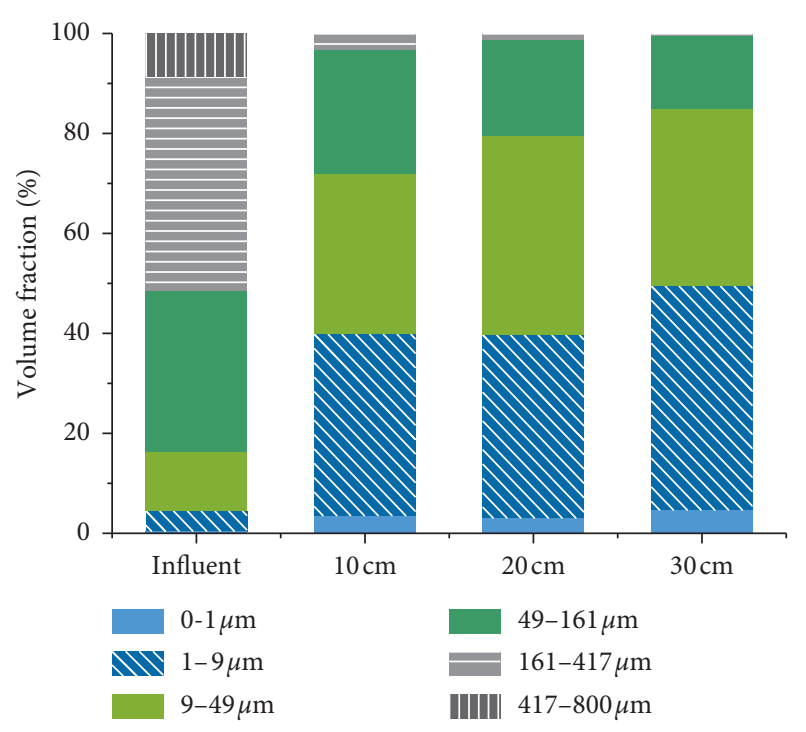

(b)

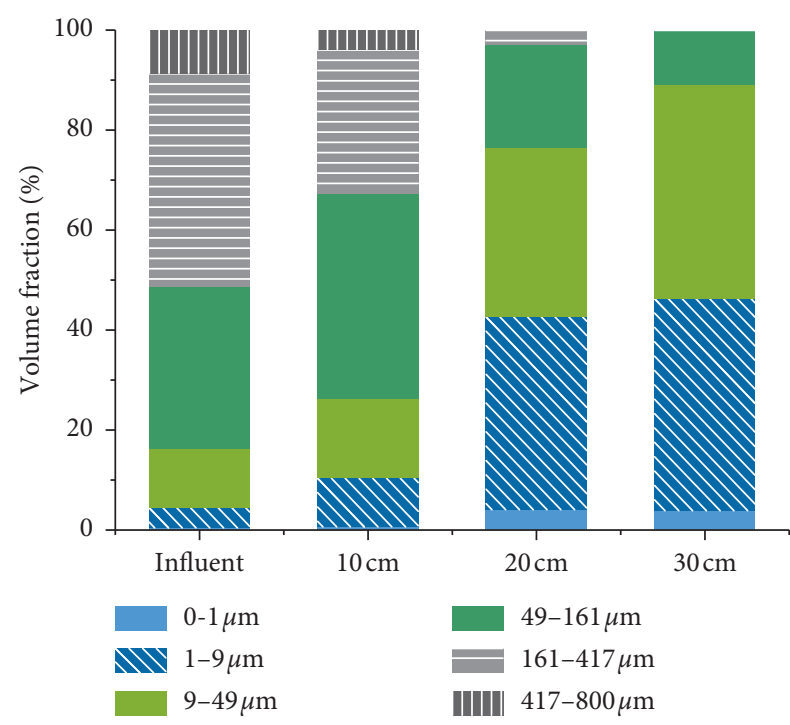

(d)

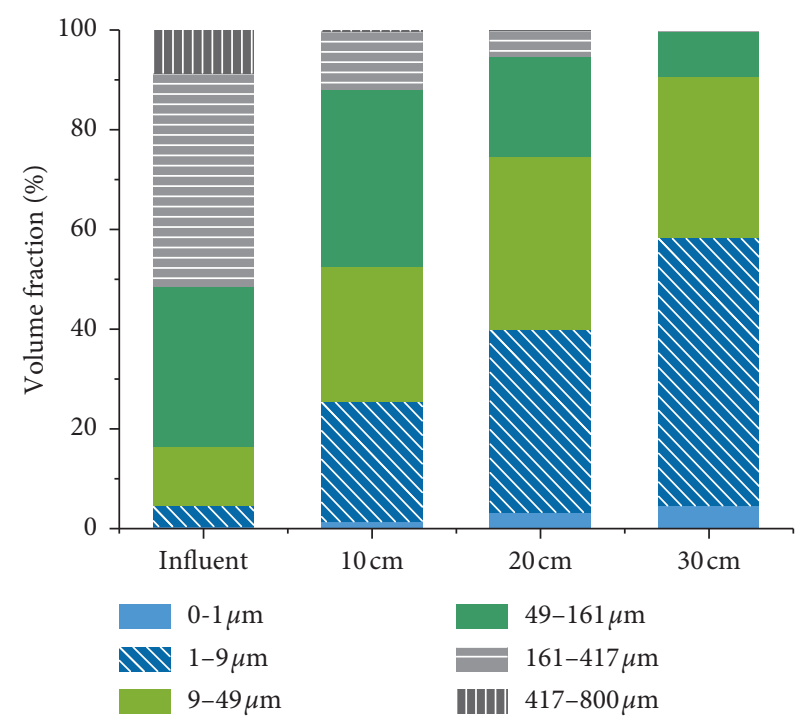

(f)

Figure 5: Continued. 


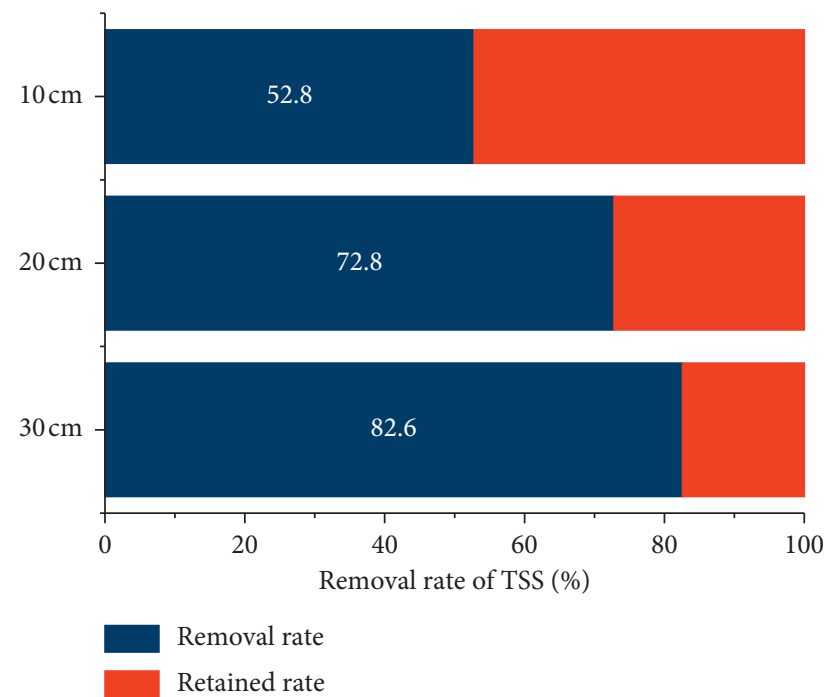

(g)

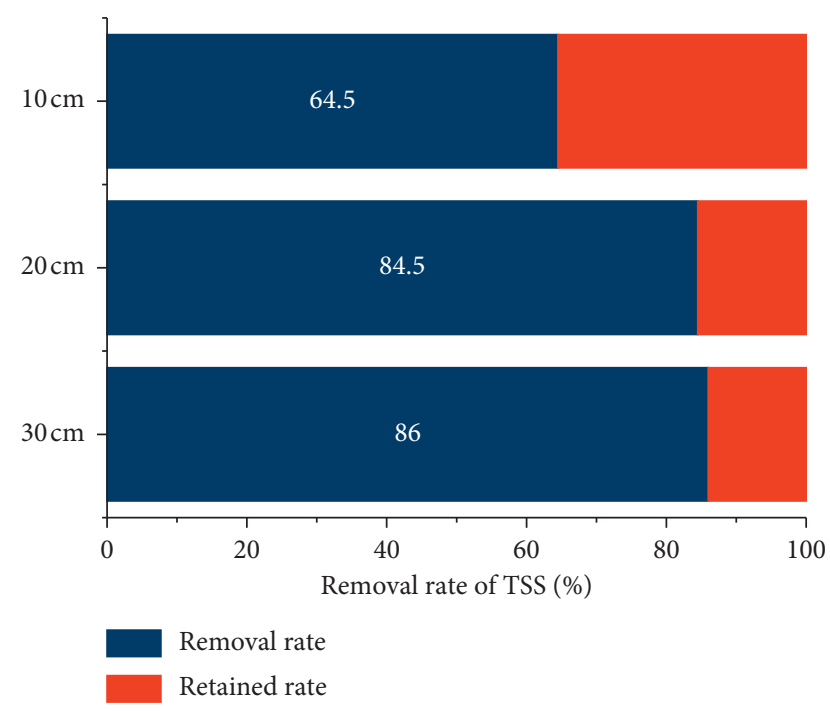

(i)

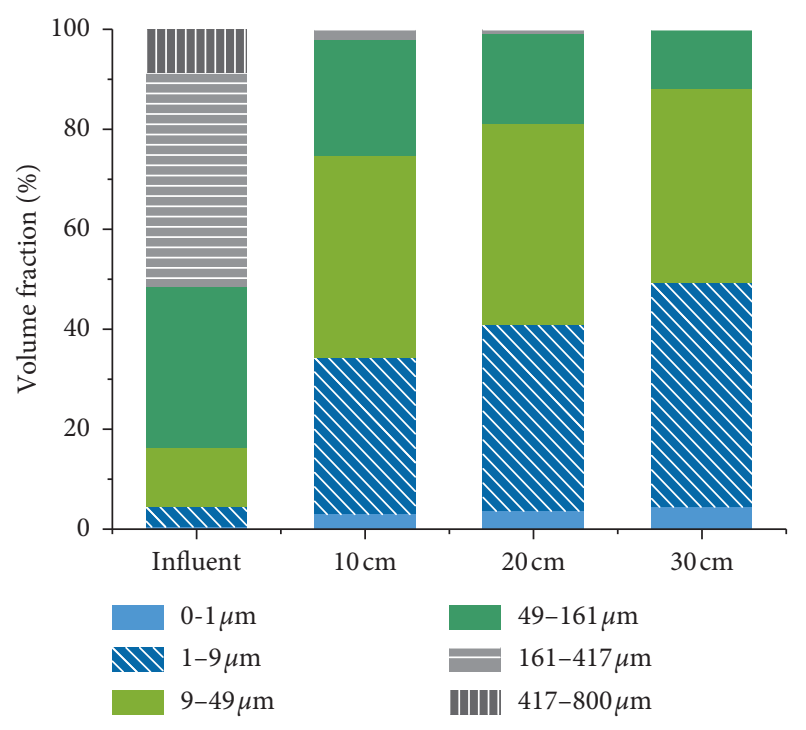

(h)

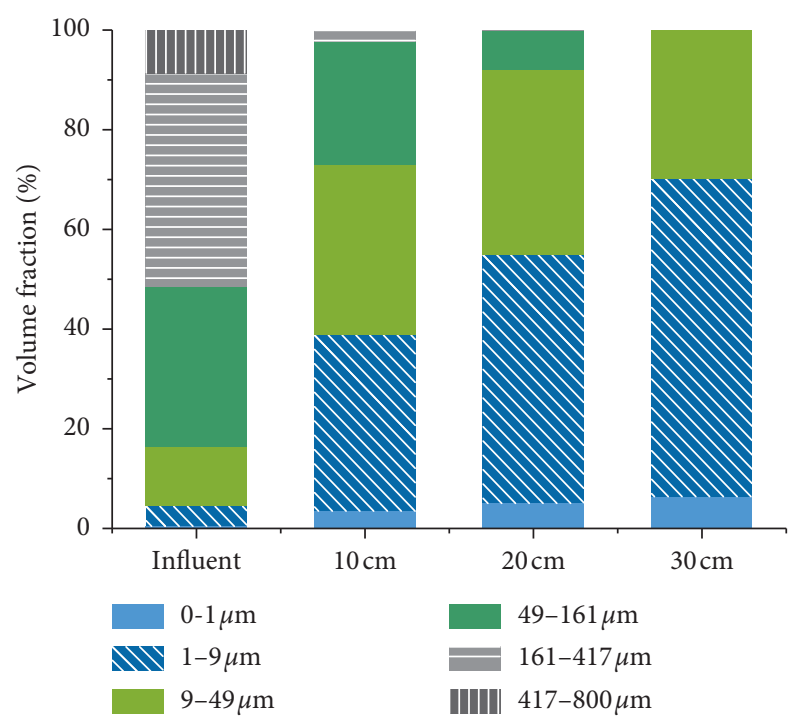

(j)

FIGURE 5: Effect of layer thickness on particle removal efficiency of different filter media. (a) TSS removal rate (Zeolite). (b) PSD based on subdivided intervals (Zeolite). (c) TSS removal rate (Ceramsite). (d) PSD based on subdivided intervals (Ceramsite). (e) TSS removal rate (Slag). (f) PSD based on subdivided intervals (Slag). (g). TSS removal rate (Diatomite). (h) PSD based on subdivided intervals (Diatomite). (i). TSS removal rate (Vesuvianite). (j) PSD based on subdivided intervals (Vesuvianite).

size range of $161-417 \mu \mathrm{m}$ could be observed when the layer thickness was $10 \mathrm{~cm}$, while almost none of these size ranges of particles could be seen when the thickness increased to $20 \mathrm{~cm}$. It means that Zeolite can remove the particulate matter with the size range of over $161 \mu \mathrm{m}$ effectively, even with the layer thickness of $10 \mathrm{~cm}$. In addition, with an increasing layer thickness, the proportions of particles with the size range of $49-161 \mu \mathrm{m}$ decreased gradually. Considering the similar removal efficiency between the thickness of $20 \mathrm{~cm}$ and $30 \mathrm{~cm}$, the thickness of $20 \mathrm{~cm}$ is suitable enough for Zeolite to remove PM.

The effect of layer thickness of Ceramsite on the particle removal efficiency is illustrated in Figures 5(c) and $5(\mathrm{~d})$. It can be seen that the removal rate of TSS increased from $73.6 \%$ to $85.8 \%$ when the layer thickness increased from $10 \mathrm{~cm}$ to $20 \mathrm{~cm}$, and it further increased to $92.7 \%$ with the layer thickness of $30 \mathrm{~cm}$. As for the effluent runoff through the Ceramsite, $3.9 \%$ of PM with the size range of $417-800 \mu \mathrm{m}$ and a big proportion (28.8\%) of PM with the size range of $161-417 \mu \mathrm{m}$ could be observed when the layer thickness was $10 \mathrm{~cm}$. The $161-417 \mu \mathrm{m}$ fraction of PM reduced sharply to $2.9 \%$ only when the thickness increased to $20 \mathrm{~cm}$, along with the $49-161 \mu \mathrm{m}$ fraction of PM decreasing significantly from $41.1 \%$ to $20.7 \%$. It means that $10 \mathrm{~cm}$ thickness of Ceramsite presents inferior capability to remove the PM with the size range of over $161 \mu \mathrm{m}$, and $20 \mathrm{~cm}$ thickness of Ceramsite shows satisfactory capability to capture the particles. 
The effect of layer thickness of Slag on the particle removal efficiency is shown in Figures 5(e) and 5(f). Comparatively, Slag presented particle removal characteristics similar to those of Zeolite. The removal rate of TSS for the Slag with each layer thickness was close. As for the effluent runoff through Slag, the 161-417 $\mu \mathrm{m}$ fraction and 49-161 $\mu \mathrm{m}$ fraction of PM decreased significantly as the layer thickness increased from $10 \mathrm{~cm}$ to $30 \mathrm{~cm}$. However, Slag showed inferior capability to capture the PM with the range over $161 \mu \mathrm{m}$, compared to Zeolite.

The effect of layer thickness of Diatomite on the particle removal efficiency is presented in Figures 5(g) and 5(h). It can be seen that the removal rate of TSS was as insufficient as $52.8 \%$ when the layer thickness was $10 \mathrm{~cm}$. The removal rate of TSS increased to $72.8 \%$ and $82.6 \%$, which was comparable to that of Zeolite and Slag, when the layer thickness increased to $20 \mathrm{~cm}$ and $30 \mathrm{~cm}$. As for the effluent runoff through the Diatomite, none of the PM with the size range of $417-800 \mu \mathrm{m}$ and a tiny proportion (2.2\%) of PM with the size range of $161-417 \mu \mathrm{m}$ could be observed when the layer thickness was $10 \mathrm{~cm}$, despite the low removal rate. Undoubtedly, the $49-161 \mu \mathrm{m}$ fraction of PM also decreased greatly as the layer thickness increased from $10 \mathrm{~cm}$ to $30 \mathrm{~cm}$. This indicates that Diatomite possesses unique capability to capture the PM with the size range of over $161 \mu \mathrm{m}$.

The effect of layer thickness of Vesuvianite on the particle removal efficiency is illustrated in Figures 5(i) and $5(j)$. It can be seen that the removal rate of TSS increased greatly from $64.5 \%$ to $84.5 \%$ as the layer thickness increased from $10 \mathrm{~cm}$ to $20 \mathrm{~cm}$. However, the removal rate remained at the same level when the layer thickness increased from 20 to $30 \mathrm{~cm}$. As for the effluent runoff through the Vesuvianite, the PSD presented similar trends to that of Diatomite. When the layer thickness was $10 \mathrm{~cm}$, none of the PM with fraction of $417-800 \mu \mathrm{m}$ and a tiny proportion (2.4\%) of PM with the size range of 161-417 $\mu \mathrm{m}$ could be observed. Moreover, all of the 49-161 $\mu \mathrm{m}$ fractions of PM were captured by Vesuvianite when the layer thickness reached $30 \mathrm{~cm}$.

Besides, the typical diameter indices of all the effluent runoff are summarized in Table 2 . It can be seen that, compared with the particles in the influent runoff, all the three diameter indices decreased sharply. This implies that all the filter media can capture coarse particles to some extent. In terms of each filter medium, the three diameter indices decreased with an increasing layer thickness. It is noticeable that when the layer thickness was $10 \mathrm{~cm}$, the $d_{50}$ and $d_{90}$ of effluent from Ceramsite and Slag were much bigger than those of the other three filter media, but the diameter indices became comparable when the layer thickness increased to $20 \mathrm{~cm}$. Effluent from Vesuvianite presented the smallest diameter indices, indicating that it possesses superior capability to capture particles.

Overall, different filter media showed great differences in particle removal characteristics, also impacted significantly by the layer thickness. When the layer thickness was $10 \mathrm{~cm}$, Ceramsite presented a higher removal rate but the fraction over $161 \mu \mathrm{m}$ of PM could not be captured effectively, while Diatomite and Vesuvianite presented the opposite trends. This indicates that both of the particle capture capability and the removal rate should be considered for filter media selection. When the layer thickness reached $20 \mathrm{~cm}$, all the five filter media showed satisfactory particle removal efficiency, and Vesuvianite presented the highest removal rate and the best capability to capture coarse particles.

3.1.2. Effect of Grain Size of Filter Media. Three grain size levels of $1-3 \mathrm{~mm}, 3-6 \mathrm{~mm}$, and $6-8 \mathrm{~mm}$ were prepared for each filter medium to investigate the effect of grain size on the particle removal efficiency. According to the layer thickness test results, $20 \mathrm{~cm}$ was selected for each filter medium in this test. Similarly, the removal rate of TSS and the particle size distribution were used to evaluate the particle removal efficiency. The results of TSS removal rate and PSD from each filter medium are illustrated in Figure 6.

The effect of grain size of Zeolite on the particle removal efficiency is shown in Figures 6(a) and 6(b). It can be seen that the grain size had a considerable impact on the removal rate. The removal rate of TSS decreased from $89.1 \%$ to $79.0 \%$ as the grain size increased from $1-3 \mathrm{~mm}$ to $3-6 \mathrm{~mm}$, and it further reduced to $69.4 \%$ as the grain size increased to 6-8 mm. Meanwhile, PSD variations could also be observed. As for the effluent runoff through Zeolite, almost none of the PM with the size range of over $161 \mu \mathrm{m}$ was observed. However, the $49-161 \mu \mathrm{m}$ fraction of PM presented a remarkable increase as the grain size increased from $1-3 \mathrm{~mm}$ to $3-6 \mathrm{~mm}$ or $6-8 \mathrm{~mm}$. This means that all grain sizes of Zeolite can capture the particles with the size range of over $161 \mu \mathrm{m}$ effectively, but Zeolite with the grain size of 1-3 mm possesses superior particle removal capability.

The effect of grain size of Ceramsite on the particle removal efficiency is illustrated in Figures 6(c) and 6(d). It can be seen that the removal rate of TSS remained at the same level for Ceramsite with the grain size of $1-3 \mathrm{~mm}$ and 3-6 $\mathrm{mm}$. However, a big drop in the removal rate could be observed when Ceramsite with the grain size of $6-8 \mathrm{~mm}$ was used. As for the effluent runoff through Ceramsite, none of the $161-800 \mu \mathrm{m}$ fractions of PM could be observed when Ceramsite with grain size of $1-3 \mathrm{~mm}$ was used. Nevertheless, there was no big difference in the PSD for Ceramsite with grain size of 3-6 mm or 6-8 $\mathrm{mm}$. The $49-161 \mu \mathrm{m}$ fraction of PM increased greatly, and the $161-417 \mu \mathrm{m}$ fraction of PM could be observed, when Ceramsite with the grain size of $3-6 \mathrm{~mm}$ and $6-8 \mathrm{~mm}$ was used. This indicates that Ceramsite with the grain size of $1-3 \mathrm{~mm}$ has superior capability to remove coarse particles.

The effect of grain size of Slag on the particle removal efficiency is shown in Figures 6(e) and 6(f). It can be seen that the grain size did impact the removal rate greatly. The removal rate of TSS reached as high as $97.7 \%$ when the grain size of $1-3 \mathrm{~mm}$ was used. Then it reduced sharply to $79.8 \%$ and $62.7 \%$ as the grain size increased to $3-6 \mathrm{~mm}$ and 6-8 mm. PSD variations also changed subsequently. As for the effluent runoff through Slag, when the grain size of $1-3 \mathrm{~mm}$ was used, the $1-9 \mu \mathrm{m}$ and $9-49 \mu \mathrm{m}$ fractions of PM accounted for $89.5 \%$ of the total particles. When the grain size of 3-6 $\mathrm{mm}$ or 6-8 $\mathrm{mm}$ was used, a small proportion of 161-417 $\mu \mathrm{m}$ fraction of PM could be observed, while the 
TABLE 2: Typical diameter indices of runoff through filter media with different layer thickness.

\begin{tabular}{lcccccccccccccccc}
\hline $\begin{array}{l}\text { Index } \\
(\mu \mathrm{m})\end{array}$ & $\begin{array}{c}\text { Influent } \\
\text { runoff }\end{array}$ & \multicolumn{3}{c}{ Zeolite } & \multicolumn{3}{c}{ Ceramsite } & \multicolumn{3}{c}{ Slag } & \multicolumn{4}{c}{ Diatomite } & \multicolumn{3}{c}{ Vesuvianite } \\
\hline$D_{10}$ & 52.3 & 2.11 & 1.76 & 1.55 & 8.81 & 2.11 & 1.97 & 3.17 & 2.22 & 1.77 & 2.63 & 1.98 & 1.86 & 2.20 & 1.83 & 1.45 \\
$D_{50}$ & 193.6 & 15.8 & 9.52 & 9.51 & 106.9 & 12.9 & 10.5 & 44.5 & 15.8 & 6.91 & 19.6 & 11.1 & 9.6 & 16.4 & 9.02 & 5.28 \\
$D_{90}$ & 400.7 & 102.8 & 64.0 & 53.9 & 310.5 & 95.7 & 51.7 & 175.2 & 117.9 & 47.24 & 88.9 & 67.3 & 52.6 & 98.5 & 47.8 & 18.3 \\
\hline
\end{tabular}

$49-161 \mu \mathrm{m}$ fraction of PM grew to $19.9 \%$ and $22.0 \%$, respectively. This implies that Slag grain sizes of $3-6 \mathrm{~mm}$ and 6-8 $\mathrm{mm}$ have equivalent capability to capture particles.

The effect of grain size of Diatomite on the particle removal efficiency is presented in Figures 6(g) and 6(h). It can be seen that the removal rate of TSS remained at the same level of around $72.8 \%-75.4 \%$ for Diatomite with the grain size of $1-3 \mathrm{~mm}$ and $3-6 \mathrm{~mm}$. However, the removal rate reduced to $57.3 \%$ when Diatomite with the grain size of 6-8 $\mathrm{mm}$ was used. Meanwhile, PSD results did not show obvious variations. As for the effluent runoff through Diatomite, none of the PM with the size range of over $161 \mu \mathrm{m}$ could be seen. The $1-9 \mu \mathrm{m}, 9-49 \mu \mathrm{m}$, and $49-161 \mu \mathrm{m}$ fractions of PM were close for Diatomite with all the three grain sizes. This indicates that Diatomite possesses excellent capability to capture the particles with the size range of over $161 \mu \mathrm{m}$, despite the differences in grain size.

The effect of grain size of Vesuvianite on the particle removal efficiency is illustrated in Figures 6(i) and 6(j). It can be seen that the grain size had a remarkable influence on the removal rate. The removal rate of TSS reduced from $97.2 \%$ to $84.5 \%$ as the grain size increased from $1-3 \mathrm{~mm}$ to $3-6 \mathrm{~mm}$, and it further reduced to $72.8 \%$ as the grain size increased to $6-8 \mathrm{~mm}$. As for the effluent runoff through Vesuvianite, there was no big difference in the PSD for the filter medium with grain size of $1-3 \mathrm{~mm}$ or $3-6 \mathrm{~mm}$. However, the $49-161 \mu \mathrm{m}$ fraction of PM increased significantly from $8 \%$ to $46.3 \%$, when the grain size of $6-8 \mathrm{~mm}$ was used. This indicates that Vesuvianite with the grain size of $6-8 \mathrm{~mm}$ has inferior capability to remove the $49-161 \mu \mathrm{m}$ fraction of PM.

Besides, the typical diameter indices of all the effluent runoff are summarized in Table 3. It can be seen that, compared with the particles in the influent runoff, all the three diameter indices decreased dramatically. This implies that all the filter media can capture coarse particles to some extent. In terms of each filter medium, the three diameter indices grew with an increasing grain size. It is noticeable that when the grain size of $6-8 \mathrm{~mm}$ was used, the $d_{50}$ of effluent from Vesuvianite was much bigger than those from other filter media. Meanwhile, the $d_{90}$ of effluent from Ceramsite and Slag was much bigger than those of other filter media. All the three diameter indices would not become comparable only when the grain size of $1-3 \mathrm{~mm}$ was used for each filter medium.

Overall, the grain size of filter media did impact the particle removal efficiency significantly. Generally, the finer the grain size is, the higher the removal efficiency will be, although Diatomite with each grain size could capture the coarse particles effectively. All the filter media with the grain size of 1-3 mm presented comparably superior capability to capture particles, but only Slag and Vesuvianite showed removal rate as high as over $90 \%$. When the grain size of 3-6 mm was used, accepted removal efficiency could be achieved for each filter medium, and Vesuvianite also presented both the highest removal rate and the best capability to capture coarse particles. When the grain size of 6-8 $\mathrm{mm}$ was used, Ceramsite and Slag showed inferior removal efficiency of PM with the size range of over $161 \mu \mathrm{m}$.

\subsection{Clogging Resistance of Different Filter Media}

3.2.1. Initial Hydraulic Conductivity of Filter Media. The airvoid fractions and initial hydraulic conductivity of the five types of filter media with three grain size levels were tested, and the results are illustrated in Figure 7.

It can be seen from Figure 7 that the grain size presented limited impact on the air-void fractions for each filter medium, though a small increase could be observed with the increase in grain size. The air-void fractions of Diatomite and Vesuvianite reached relatively high values of $62 \%$ and $60 \%$, respectively, while air-void fractions of Zeolite, Ceramsite, and Slag remained at the levels of $45 \%-50 \%$. As for the initial hydraulic conductivity, just a slight growth could be observed as the grain size increased. Ceramsite presented much higher hydraulic conductivity of around $6.3 \mathrm{~mm} / \mathrm{s}$, while hydraulic conductivity was around $4.5 \mathrm{~mm} / \mathrm{s}$ for Zeolite and Diatomite, and around $5.0 \mathrm{~mm} / \mathrm{s}$ for Slag and Vesuvianite. This indicates that hydraulic conductivity may depend on not only the air-void fractions, but also the microstructure of filter media. Ceramsite possesses some parts of smooth surface in micro texture (Figure 3(b)), which can accelerate the flow rate, leading to the high hydraulic conductivity.

\subsubsection{Long-Term Clogging Characteristics of Different Filter} Media. According to the results in Section 3.1, the layer thickness and grain size had significant impact on the particle removal efficiency. For comparison study, each filter medium with the same layer thickness of $20 \mathrm{~cm}$ and grain size of $3-6 \mathrm{~mm}$ was selected for this clogging test. The retained ratio of hydraulic conductivity $\varphi$ and the removal rates of pollutants are plotted against simulation time in Figure 8 .

It can be seen from Figure 8 that the hydraulic conductivity presented roughly a downward trend over simulation time. For all filter media, retained ratio of hydraulic conductivity $\varphi$ decreased rapidly at the first 3-4 years, indicating a fast clogging stage. Then, $\varphi$ remained stable or even recovered a little bit for the next 1-2 years, indicating a 


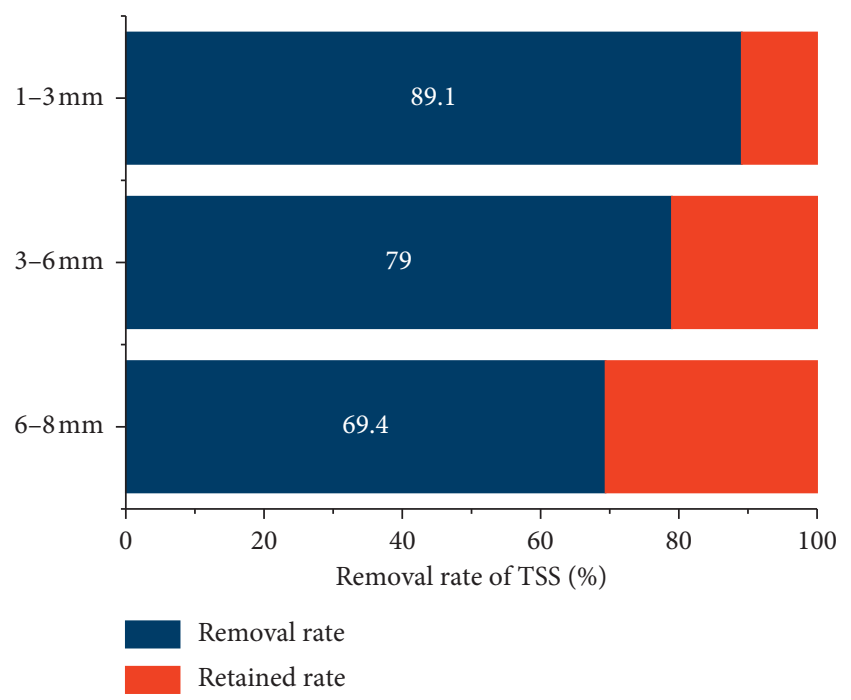

(a)

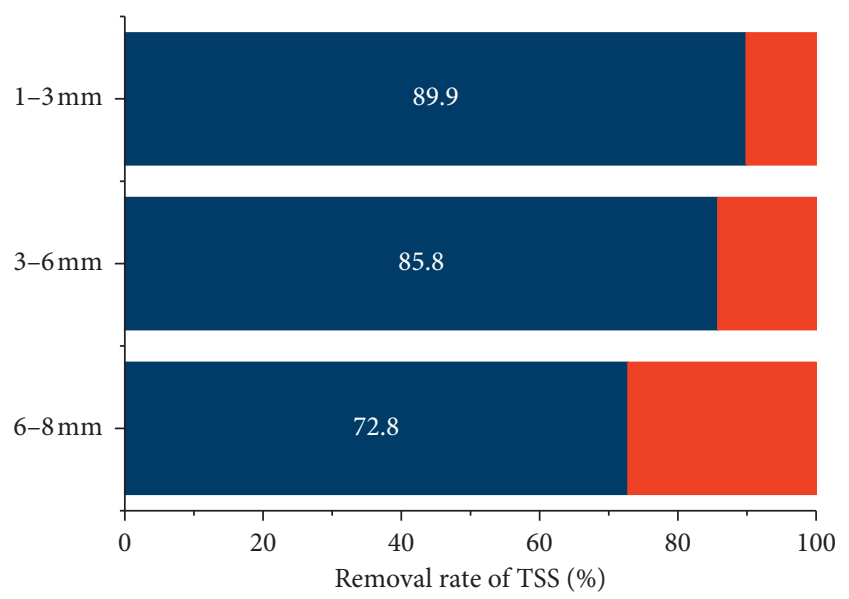

Removal rate

Retained rate

(c)

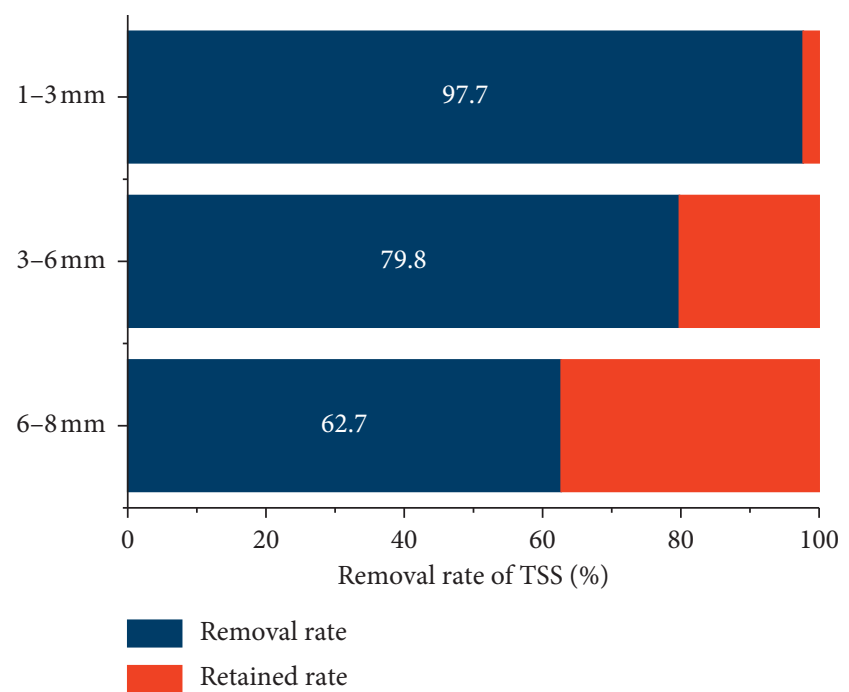

(e)

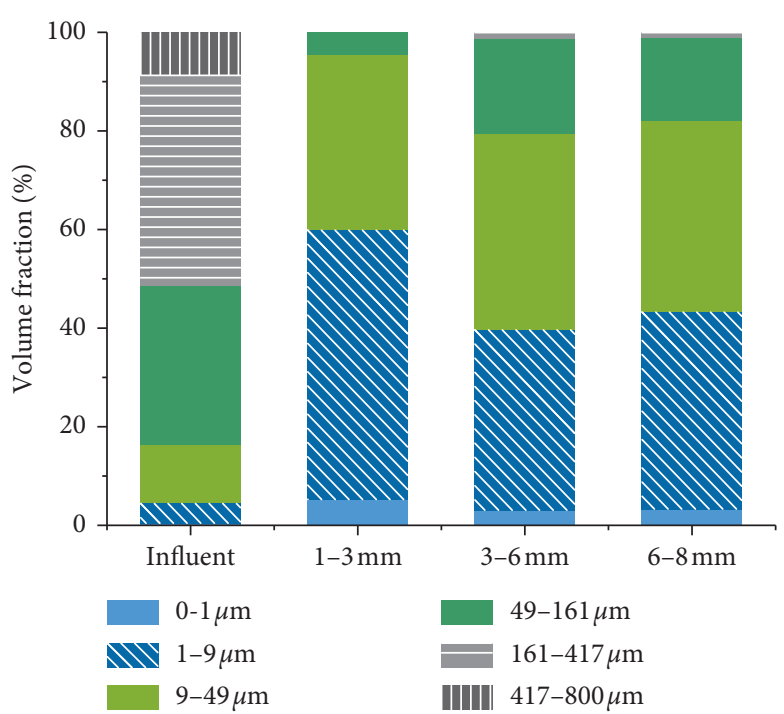

(b)

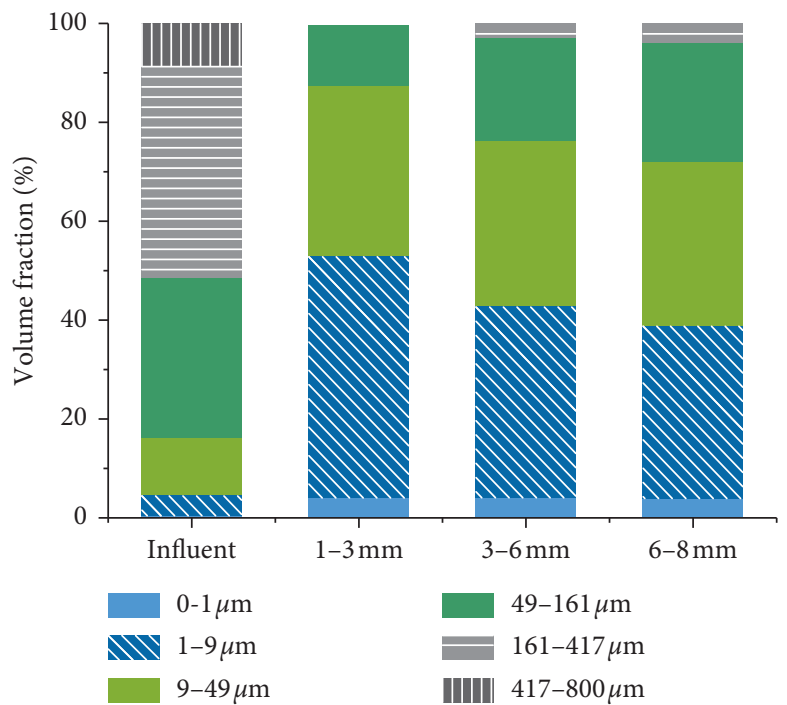

(d)

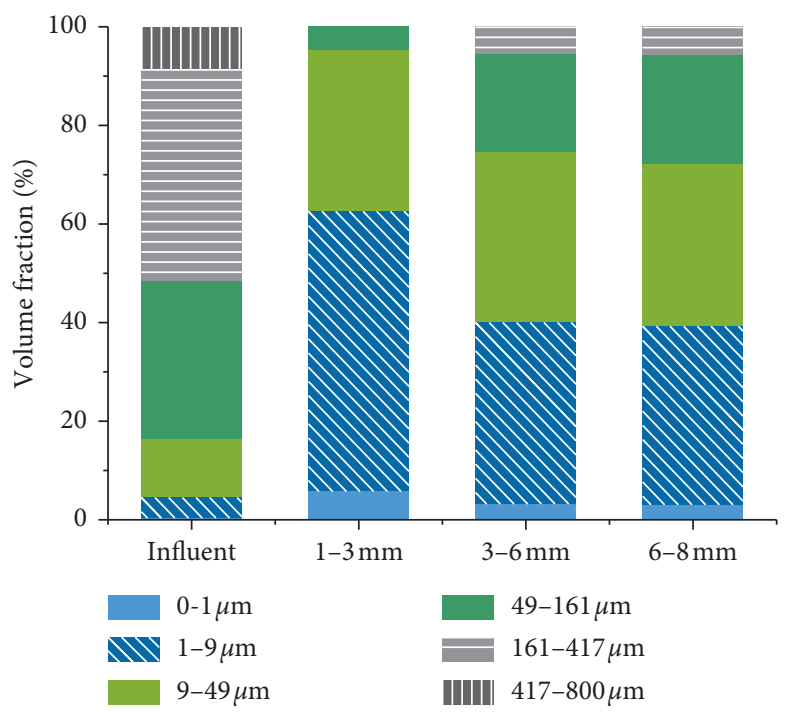

(f)

Figure 6: Continued. 


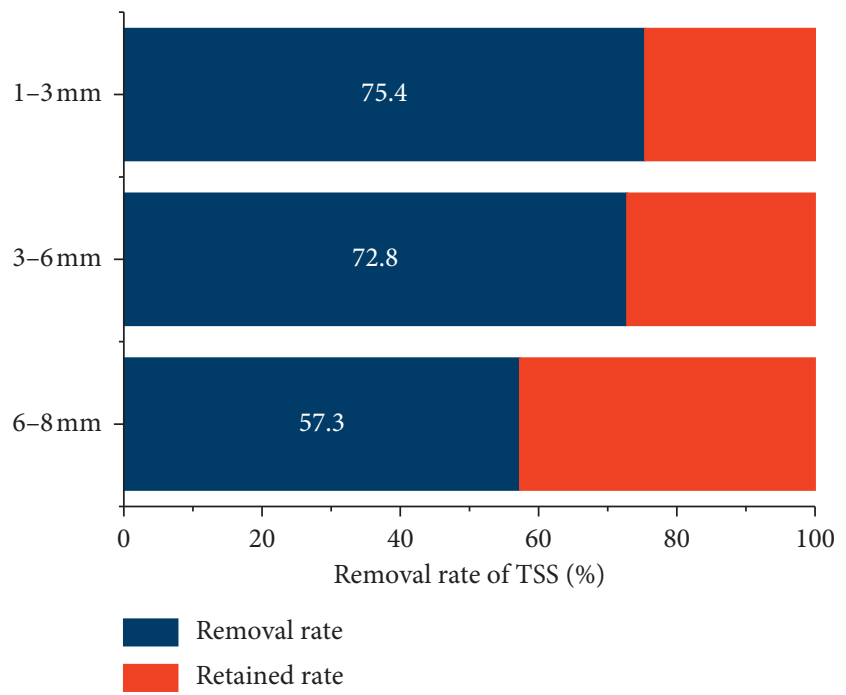

(g)

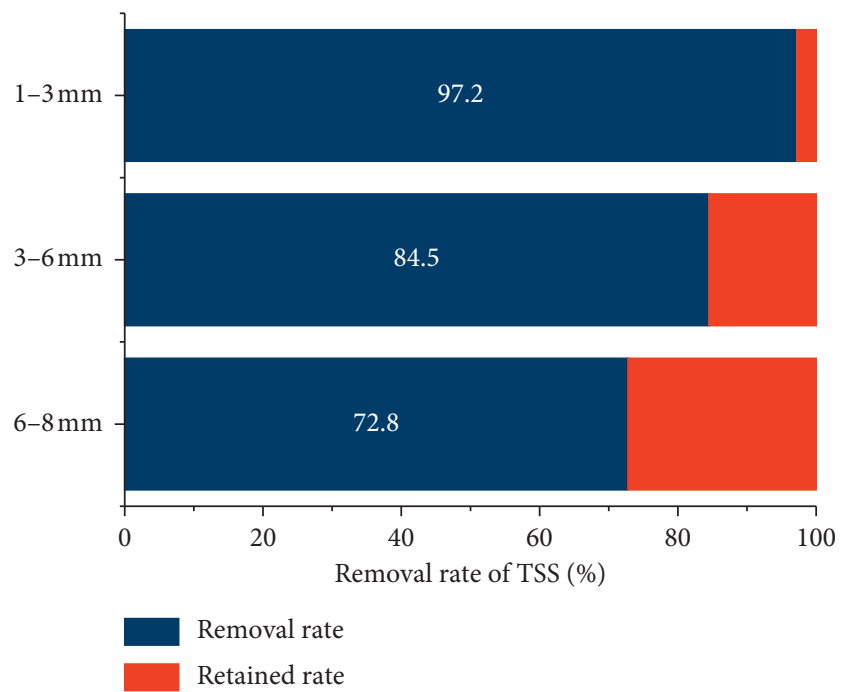

(i)

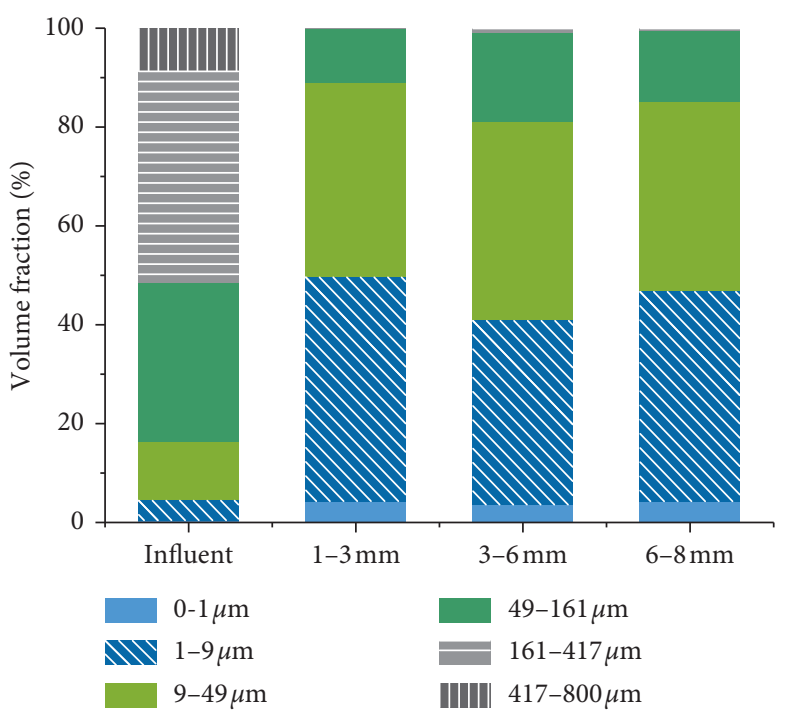

(h)

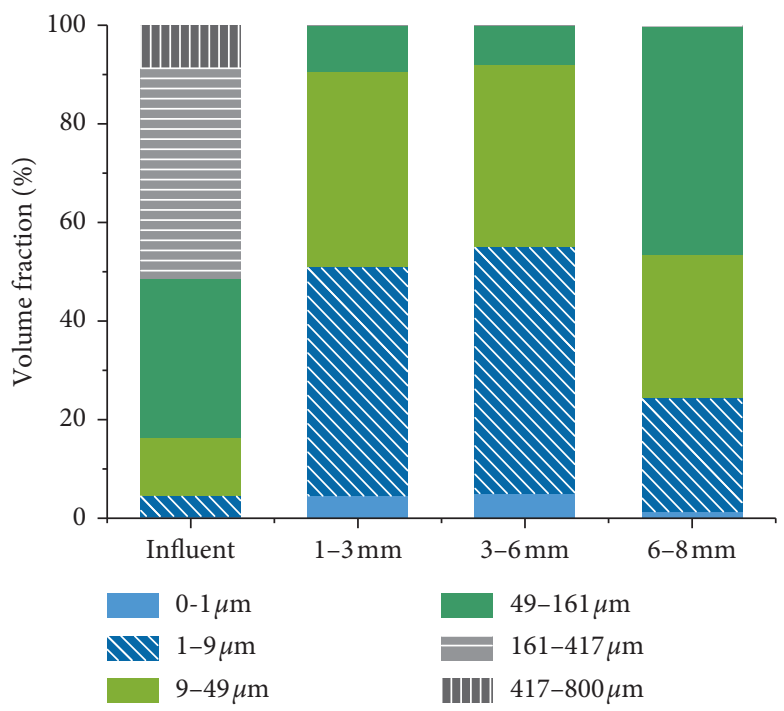

(j)

FIGURE 6: Effect of grain size on particle removal efficiency of different filter media. (a) TSS removal rate (Zeolite). (b) PSD based on subdivided intervals (Zeolite). (c) TSS removal rate (Ceramsite). (d) PSD based on subdivided intervals (Ceramsite). (e) TSS removal rate (Slag). (f) PSD based on subdivided intervals (Slag). (g) TSS removal rate (Diatomite). (h) PSD based on subdivided intervals (Diatomite). (i) TSS removal rate (Vesuvianite). (j) PSD based on subdivided intervals (Vesuvianite).

TABLE 3: Typical diameter indices of runoff through filter media with different layer thickness.

\begin{tabular}{lcccccccccccccccc}
\hline \multirow{2}{*}{ Index $(\mu \mathrm{m})$} & \multirow{2}{*}{ Influent runoff } & \multicolumn{3}{c}{ Zeolite } & \multicolumn{4}{c}{ Ceramsite } & \multicolumn{3}{c}{ Slag } & \multicolumn{4}{c}{ Diatomite } & \multicolumn{3}{c}{ Vesuvianite } \\
& & $1-3$ & $3-6$ & $6-8$ & $1-3$ & $3-6$ & $6-8$ & $1-3$ & $3-6$ & $6-8$ & $1-3$ & $3-6$ & $6-8$ & $1-3$ & $3-6$ & $6-8$ \\
\hline$D_{10}$ & 52.3 & 1.63 & 1.76 & 2.27 & 1.88 & 2.11 & 2.61 & 1.53 & 2.22 & 2.53 & 1.90 & 1.98 & 2.24 & 1.69 & 1.83 & 3.56 \\
$D_{50}$ & 193.6 & 6.66 & 9.52 & 12.5 & 8.37 & 12.9 & 22.0 & 6.4 & 15.8 & 16.4 & 9.54 & 11.1 & 14.0 & 7.73 & 9.02 & 45.5 \\
$D_{90}$ & 400.7 & 33.4 & 64.0 & 77.5 & 57.5 & 95.7 & 136.0 & 32.3 & 117.9 & 127.2 & 53.3 & 67.3 & 72.5 & 43.2 & 47.8 & 94.0 \\
\hline
\end{tabular}

stable clogging stage. Afterwards, $\varphi$ showed a slow declining trend for the remaining simulation periods, indicating a gradual clogging stage. At the end of the 8-year simulation, $\varphi$ was only $35 \%, 26 \%, 31 \%, 19 \%$, and $39 \%$ for Zeolite,
Ceramsite, Slag, Diatomite, and Vesuvianite, respectively. This implies that Vesuvianite possesses superior clogging resistant property, while Diatomite is more prone to clogging. 


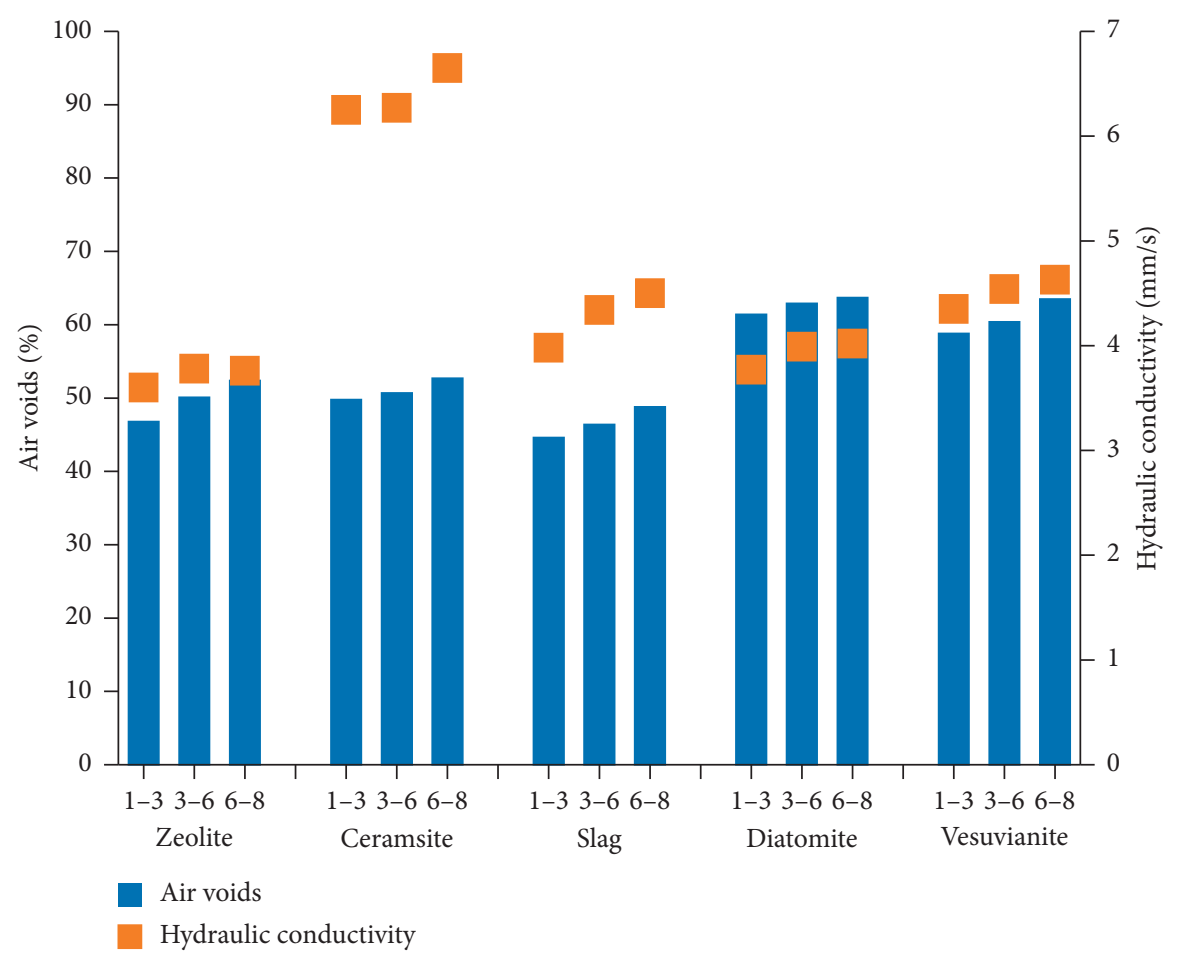

FIgURe 7: Air-void fractions and initial hydraulic conductivity of different filter media.
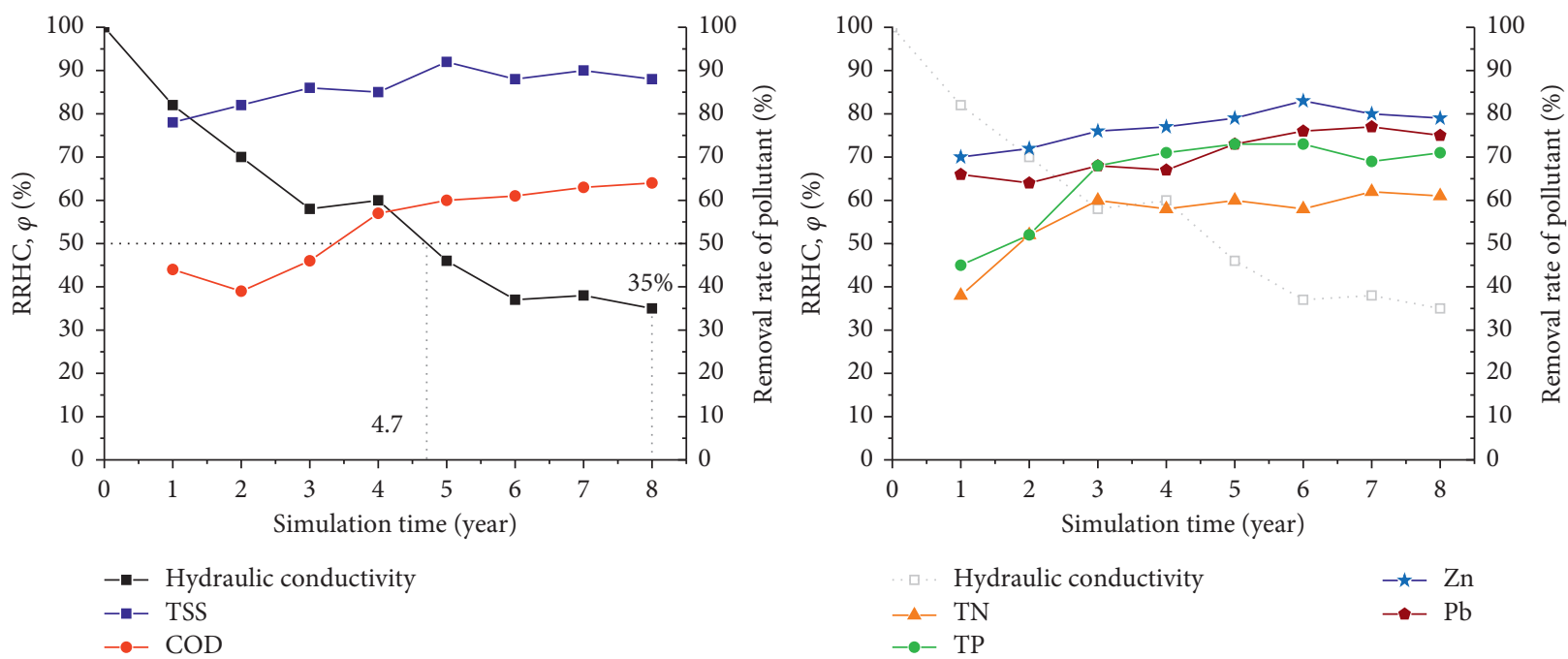

(a)

Figure 8: Continued. 

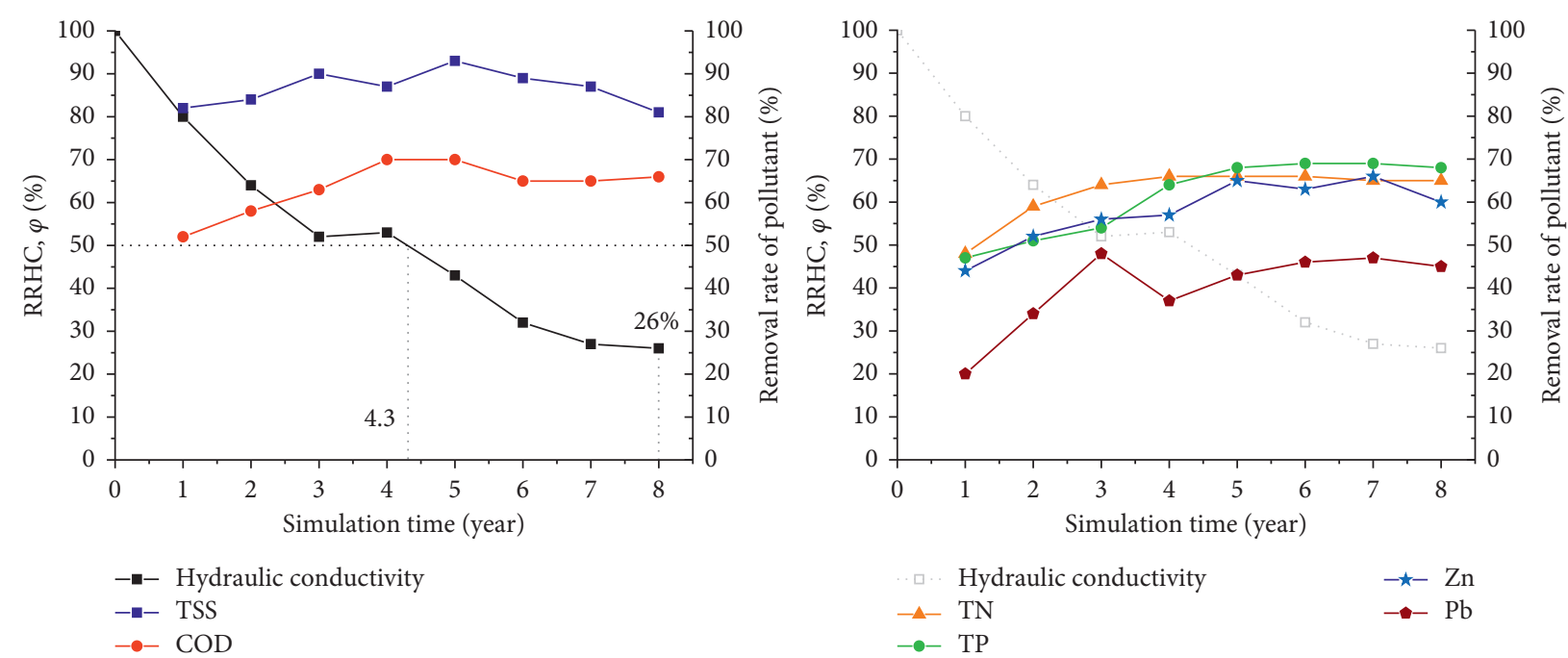

(b)
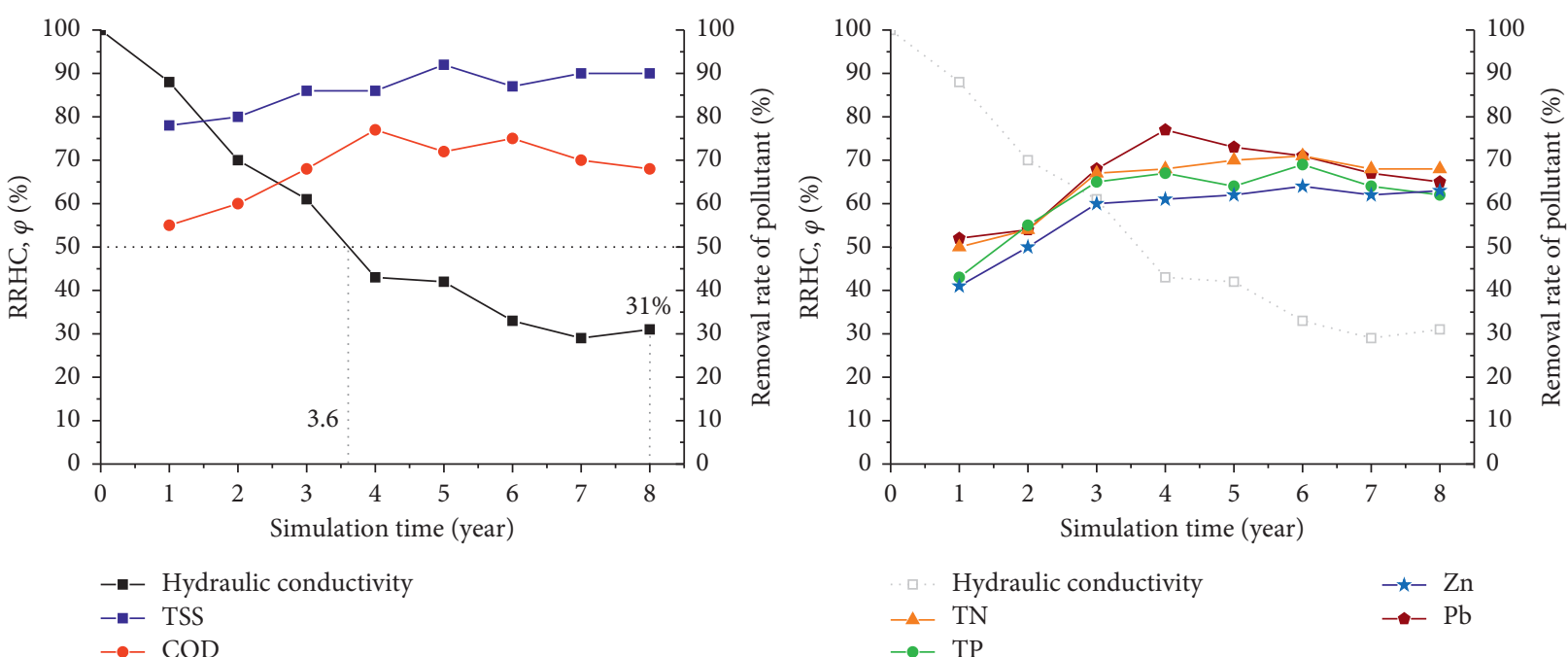

(c)
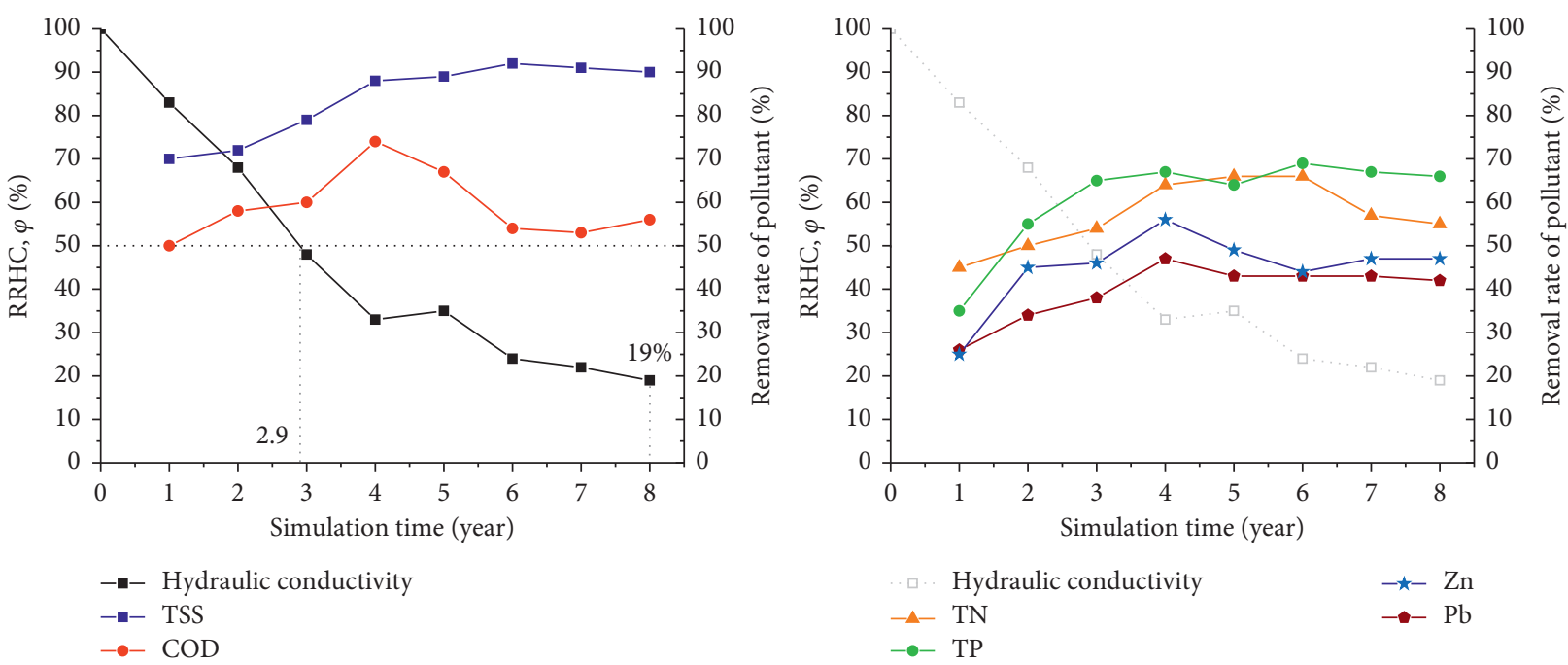

(d)

FIgURe 8: Continued. 

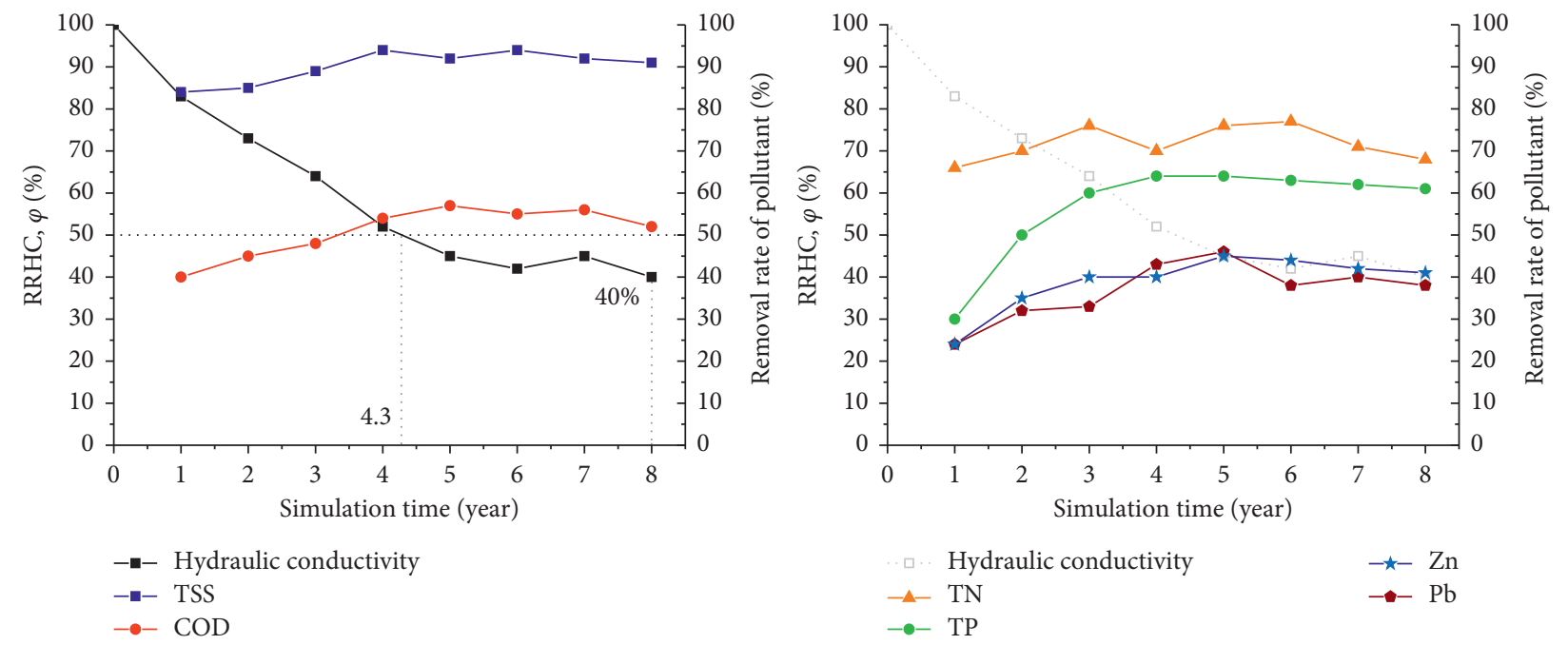

(e)

FIGURE 8: Long-term clogging test results of different filter media. Variations of hydraulic conductivity and pollutant concentration with simulation time: (a) Zeolite, (b) Ceramsite, (c) Slag, (d) Diatomite, and (e) Vesuvianite.

In terms of all the detected types of pollutants, the removal rates increased at the fast clogging stage and then remained at the same levels as the clogging progress developed, which was consistence with the results in $[8,11]$. This shows that the filtration capability of the filter media to capture the pollutants enhanced at the fast clogging stage, and then the filtration capability remained though the clogging phenomena became more and more severe. The explanation could be that the retained particulate matter by filter media can capture more pollutants due to their relative bigger specific surface areas. Besides, the flow rate of the runoff could be slowed down due to the deterioration in hydraulic conductivity caused by clogging, which also could contribute to the higher pollutant removal rates.

As for the stable clogging stage, the retained ratio of hydraulic conductivity $\varphi$ remained stable or even increased slightly. This is owing to unstable state of the retained particulate matter within the filter media. Those parts of PM could be washed away through interlocking pore in the filter media, indicating that this clogging stage could be recovered since no permanent clogging has been formed. As a result, this can be considered as the optimum timing to maintain the filter media, so as to recover the air voids and keep a balance between hydraulic conductivity and filtration capability. Therefore, according to the changes in hydraulic conductivity over simulation time, it was proposed that the best maintenance timing is when $\varphi$ reduced to $50 \%$ of its initial value. As shown in Figure 8, marked as dot dash lines, when the retained ratio of hydraulic conductivity $\varphi$ reduced to $50 \%$, it took $4.7,4.3$, 3.6, 2.9, and 4.3 years for Zeolite, Ceramsite, Slag, Diatomite, and Vesuvianite, respectively. It is worthwhile to point out that the particle removal rate is not related to the clogging resistance of filter media. For instance, Diatomite presented the lowest particle removal rate of $72.8 \%$, which

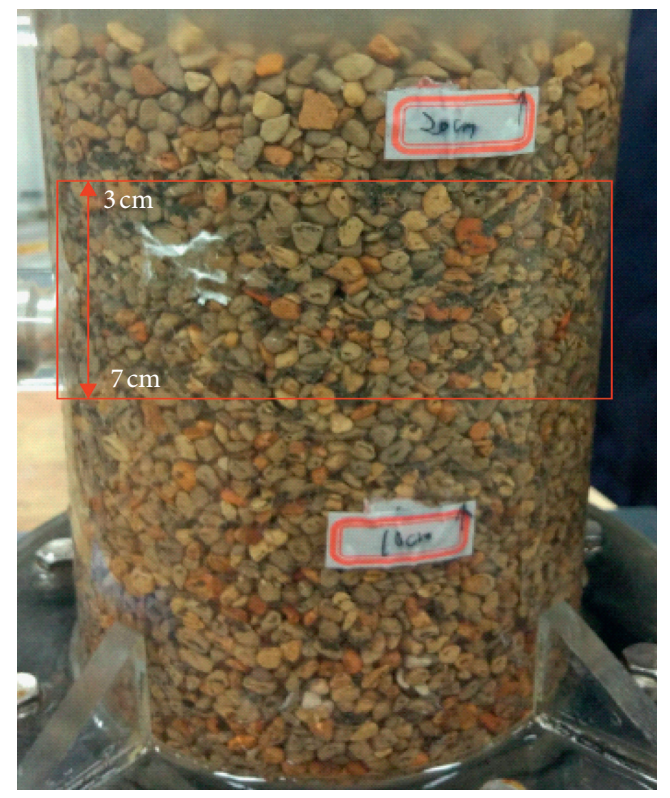

Figure 9: Deposited position of captured particulate matter.

meant that this medium captured the least amount of particulate matter. However, it was more prone to clogging and needed maintenance only after 2.9 years of operation. Ceramsite and Vesuvianite possessed higher particle removal rate of around $85 \%$, but maintenance would not be necessary till 4.3 years of operation. This phenomenon could be caused by the differences in the microstructure of filter media.

In addition, it was found that most of the visible particulate matter was captured within the depth of $3 \mathrm{~cm}-7 \mathrm{~cm}$ (Figure 9) since the filter media on the top $3 \mathrm{~cm}$ were floated caused by the "washing effect" of the runoff, which was consistent with the result from [28]. 


\section{Conclusions}

This study focused on evaluating the capability to capture particulate matter and clogging characteristics of five types of filter media. Long-term clogging tests were performed for each filter medium by self-developed equipment. The conclusions can be derived as follows.

(1) Different types of filter media present various capabilities to capture particulate matter, resulting in the differences in the TSS removal rate and PSD of captured PM.

(2) The capability of different filter media to capture PM is also layer thickness and grain size dependent. Generally, a thicker layer and finer grain size would be more effective in capturing PM.

(3) All the five types of filter media can capture all the particulate matter with the size range of $161-800 \mu \mathrm{m}$ and most of the particles with the size range of 49-161 $\mu \mathrm{m}$ when suitable filter media are used, indicating that the PM with the size of over $49 \mu \mathrm{m}$ is dominant in clogging.

(4) The clogging process of each filter medium develops rapidly at the first 3-4 years and then presents a slow decreasing trend. To prevent permanent clogging, the proposed maintenance timing for Zeolite, Ceramsite, Slag, Diatomite, and Vesuvianite is after $4.7,4.3,3.6,2.9$, and 4.3 years' operation, respectively.

(5) Higher TSS removal rate may not result in more rapid clogging phenomenon. Vesuvianite possesses both superior capability to capture particulate matter and clogging resistance. Therefore, both TSS removal rate and clogging resistance should be taken into consideration for filter media selection.

\section{Data Availability}

The data used to support the findings of this study are available from the corresponding author upon request.

\section{Conflicts of Interest}

The authors declare that there are no conflicts of interest regarding the publication of this paper.

\section{Acknowledgments}

The authors wish to express their appreciation for the support received from the National Natural Science Foundation of China (51578481) and Jiangsu Overseas Visiting Scholar Program for University Prominent Young \& Middle-Aged Teachers and Presidents.

\section{References}

[1] J. Vaze and F. H. S. Chiew, "Nutrient loads associated with different sediment sizes in urban stormwater and surface pollutants," Journal of Environmental Engineering, vol. 130, no. 4, pp. 391-396, 2004.

[2] E. Risch, J. Gasperi, M.-C. Gromaire et al., "Impacts from urban water systems on receiving waters - how to account for severe wet-weather events in LCA?" Water Research, vol. 128, pp. 412-423, 2018.

[3] P. Zhang, Y. Cai, and J. Wang, "A simulation-based real-time control system for reducing urban runoff pollution through a stormwater storage tank," Journal of Cleaner Production, vol. 183, pp. 641-652, 2018.

[4] USEPA, "Environmental indicators of water quality in the United States," Art Panorama, vol. 235, no. 3, pp. 1823-1828, 2006.

[5] G. Straffelini, R. Ciudin, A. Ciotti, and S. Gialanella, "Present knowledge and perspectives on the role of copper in brake materials and related environmental issues: A critical assessment," Environmental Pollution, vol. 207, pp. 211-219, 2015.

[6] N. C. Okochi and D. W. McMartin, "Laboratory investigations of stormwater remediation via slag: Effects of metals on phosphorus removal," Journal of Hazardous Materials, vol. 187, no. 1-3, pp. 250-257, 2011.

[7] H. S. Kandra, D. McCarthy, T. D. Fletcher, and A. Deletic, "Assessment of clogging phenomena in granular filter media used for stormwater treatment," Journal of Hydrology, vol. 512, pp. 518-527, 2014.

[8] B. E. Hatt, N. Siriwardene, A. Deletic, and T. D. Fletcher, "Filter media for stormwater treatment and recycling: The influence of hydraulic properties of flow on pollutant removal," Water Science \& Technology, vol. 54, no. 6-7, pp. 263-271, 2006.

[9] A. Parvan, S. Jafari, M. Rahnama, S. N. apourvari, and A. Raoof, "Insight into particle retention and clogging in porous media; A pore scale study using lattice Boltzmann method," Advances in Water Resources, vol. 138, Article ID 103530, 2020.

[10] B. E. Hatt, T. D. Fletcher, and A. Deletic, "Treatment performance of gravel filter media: Implications for design and application of stormwater infiltration systems," Water Research, vol. 41, no. 12, pp. 2513-2524, 2007.

[11] H. Li, A. P. Davis, and F. Asce, "Urban particle capture in bioretention media. I: Laboratory and field studies," Journal of Environmental Engineering, vol. 134, no. 6, pp. 409-418, 2008.

[12] N. Siriwardene, A. Deletic, and T. Fletcher, "Clogging of stormwater gravel infiltration systems and filters: Insights from a laboratory study," Water Research, vol. 41, no. 7, pp. 1433-1440, 2007.

[13] A. Kang, H. Mao, B. Li, C. Kou, X. Xu, and B. Jahangiri, "Investigation of selective filtration characteristics of filter media for pavement runoff treatment," Journal of Cleaner Production, vol. 235, pp. 590-602, 2019.

[14] X. Hu, K. Dai, and P. Pan, "Investigation of engineering properties and filtration characteristics of porous asphalt concrete containing activated carbon," Journal of Cleaner Production, vol. 209, pp. 1484-1493, 2019.

[15] N. Hu, J. Zhang, S. Xia et al., "A field performance evaluation of the periodic maintenance for pervious concrete pavement," Journal of Cleaner Production, vol. 263, no. No, 121463 pages, 2020.

[16] Y. Ma, X. Chen, Y. Geng, and X. Zhang, "Effect of clogging on the permeability of porous asphalt pavement," Advances in Materials Science and Engineering, vol. 2020, Article ID 4851291, pp. 1-9, 2020. 
[17] S. Alber, W. Ressel, P. Liu, G. Lu, D. Wang, and M. Oeser, "Analyzing the effects of clogging of PA internal structure with artificial soiling experiments," International Journal of Transportation Science and Technology, vol. 8, no. 4, pp. 383-393, 2019.

[18] G. Lu, Z. Wang, P. Liu, D. Wang, and M. Oeser, "Investigation of the hydraulic properties of pervious pavement mixtures: characterization of Darcy and non-Darcy flow based on pore microstructures," Journal of Transportation Engineering, Part B: Pavements, vol. 146, no. 2, Article ID 04020012, 2020.

[19] H. Wang, J. Xin, X. Zheng et al., "Clogging evolution in porous media under the coexistence of suspended particles and bacteria: Insights into the mechanisms and implications for groundwater recharge," Journal of Hydrology, vol. 582, Article ID 124554, 2020.

[20] J. Fetzer, M. Holzner, M. Plötze, and G. Furrer, "Clogging of an Alpine streambed by silt-sized particles - Insights from laboratory and field experiments," Water Research, vol. 126, pp. 60-69, 2017.

[21] F. J. Charters, T. A. Cochrane, and A. D. O'Sullivan, "Particle size distribution variance in untreated urban runoff and its implication on treatment selection," Water Research, vol. 85, pp. 337-345, 2015.

[22] Z. Shen, J. Liu, G. Aini, and Y. Gong, "A comparative study of the grain-size distribution of surface dust and stormwater runoff quality on typical urban roads and roofs in Beijing, China," Environmental Science and Pollution Research, vol. 23, no. 3, pp. 2693-2704, 2016.

[23] R. J. Winston and W. F. Hunt, "Characterizing runoff from roads: Particle size distributions, nutrients, and gross solids," Journal of Environmental Engineering, vol. 143, no. 1, Article ID 04016074, 2017.

[24] Y. Li, S.-L. Lau, M. Kayhanian, and M. K. Stenstrom, "Particle size distribution in highway runoff," Journal of Environmental Engineering, vol. 131, no. 9, pp. 1267-1276, 2005.

[25] M. Jartun, R. Tore, E. Steinnes, and T. Volden, "Runoff of particle bound pollutants from urban impervious surfaces studied by analysis of sediments from stormwater traps," Science of the Total Environment, vol. 396, no. 2-3, pp. 147$163,2008$.

[26] C. Wang, H. Wang, M. Oeser, and M. R. Mohd Hasan, "Investigation on the morphological and mineralogical properties of coarse aggregates under VSI crushing operation," International Journal of Pavement Engineering, vol. 2020, Article ID 1714043, pp. 1-14, 2020.

[27] H. Wang, C. Wang, Y. Bu, Z. You, X. Yang, and M. Oeser, "Correlate aggregate angularity characteristics to the skid resistance of asphalt pavement based on image analysis technology," Construction and Building Materials, vol. 242, Article ID 118150, 2020.

[28] E. Q. Segismundo, B.-S. Lee, L.-H. Kim, and B.-H. Koo, "Evaluation of the impact of filter media depth on filtration performance and clogging formation of a stormwater sand filter," Journal of Korean Society on Water Environment, vol. 32, no. 1, pp. 36-45, 2016. 